\title{
Conpsumptionscapes: videogame stereotypes and Latin-American cities environments. Case: Uncharted 3: Drake's Deception / Uncharted 4: The Thief End
}

\author{
Claudio Rossi \\ Universidad de Los Andes, Colombia. Faculty of Architecture and Design \\ Politecnico di Torino, Italy. Architecture and Design Department, \\ e-mail: cj.rossi44@uniandes.edu.co \\ ORCID iD: https://orcid.org/0000-0003-4715-603X
}

Submitted: 7 October 2018. Accepted: 20 June 2019

\begin{abstract}
The consumption landscape refers to the context in which the daily basic needs of a society are determined. The small store in the neighborhood and the street market are architectural structures or urban spaces which shape the lives of cities as we know them today. Shopping centres are the evolution of these building formats and can characterize contemporary life. The exercise proposed by this article is to review the condition of the contexts of consumption in which the narrative of video games are developed through the study and selection of cases (Uncharted 3: Drake's Deception / Uncharted 4: A Thief's End). These demonstrate that the urban landscape with which our cities are represented appears as scenarios loaded with stereotypes. The emphasis of this research is on the representation of the historical Latin American city as a spatially modelled and stereotyped territory where the narrative is contextualized. This article does not focus on how the story develops within a commercial space but instead proposes a transversal idea that the consumption contexts are landscapes determined by cultural logics where the plot occurs. Consumption landscapes are the simultaneous spatial, cultural and historical constructions that give meaning to a narrative and represent an augmented reality of our cities: extensive, immersive and suggestive, but also perverse.
\end{abstract}

KEYWORDS: Videogame scenarios; Landscapes; Latin-American city; Consumptionscapes; Stereoscapes; Representation.

Citation / Cómo citar este artículo: Rossi, Claudio (2020) "Conpsumptionscapes: videogame stereotypes and LatinAmerican cities environments Case: Uncharted 3: Drake's Deception / Uncharted 4: The Thief End" Culture \& History Digital Journal, 9 (1): 003. https://doi.org/10.3989/chdj.2020.003

RESUMEN: Conpsumptionscapes: estereotipos de videojuegos y ambientes urbanos de Latinoamérica. Casos de estudio: Uncharted 3: Drake's Deception / Uncharted 4: The Thief End.- El paisaje de consumo se refiere al contexto en el que las necesidades básicas de una sociedad se determinan diariamente. La pequeña tienda en el barrio y el mercado de calle, son estructuras arquitectónicas o espacios urbanos, que dieron forma a la vida de las ciudades como la conocemos hoy. Los centros comerciales son la evolución de estos formatos de construcción y pueden caracterizar la vida contemporánea. El ejercicio propuesto por este artículo es revisar la condición de los contextos de consumo en los que se desarrolla la narrativa de los videojuegos a través del estudio y la selección de casos (Uncharted 3: Drake's Deception / Uncharted 4: A Tief's End) que demuestran que, el paisaje urbano con el que se representan nuestras ciudades aparece como un contexto cargado de estereotipos donde la vida cotidiana tiene lugar. El foco de la investigación está en la representación de la ciudad histórica latinoamericana como un territorio modelado espacialmente y estereotipada como un contexto narrativo jugable. No es importante determinar si la historia se desarrolla dentro de un espacio comercial, sino proponer la idea transversal de que los contextos de consumo que estructuran dichos paisajes y que determinan las lógicas culturales donde se desarrolla la trama. Los paisajes de consumo son la construcción espacial, cultural e histórica (al mismo tiempo) que da sentido a 
la narrativa y representa una realidad aumentada de nuestras ciudades: extensa, inmersiva y sugerente, pero también perversa.

PALABRAS CLAVE: Escenarios del videojuego; Paisajes; Ciudad Latinoamericana; Consumptionscapes; Stereoscapes; Representación.

Copyright: (C) 2020 CSIC. This is an open-access article distributed under the terms of the Creative Commons Attribution 4.0 International (CC BY 4.0) License.

\section{"The work of design necessarily supposes a gallery of mental pictures." \\ F. L.Olmstead, 1861 (emphasis added) $)^{1}$}

The video game is an emerging cultural product that has become an object of study for interdisciplinary research with narratological and playful (ludological) approaches. Its condition as a form of entertainment, makes its consumption, production, and distribution, a growing and increasingly influential phenomenon. For this reason, the digital experience has become an essential part of contemporary culture, not only as a visual medium but also in more traditional artistic fields (Chávez, 2010)

This technologically mediated "world" of a video game create digital scenarios with theatrical spaces, narratives, and historical metaphors that support players in immersing themselves into the gameplay (Chávez, 2010). The architectural and urban references implemented in video games also work as mechanisms to aid exploration of human interaction with those virtual worlds. These features constitute a digital language that adapts the perceptions of gamers to these spatial environments. By using images and sounds, game designers provide players a sense of the essential characteristics of the fictional spaces they play within (Pérez Indaverea, 2012).

In this sense, the urban space in videogames has its own vocabulary that builds a functional whole, providing an experience that is obtained not only from direct contact, but also integrated with different forms of visual reproduction of these environments. An immersive narrative experience built around these environments allows players to explore the vast ludic dynamics contained in the digital city (Papadopoulos y Malakasioti, 2012). The scenarios ${ }^{2}$ represented in this medium, are a fundamental part of the exploration of certain videogames. This navigation within digital environments promotes a recognition by the player of the elements that constitute the environments of the game, but at the same time provides a playable territory where they experience and produce relationships with the real world. The scenarios are bridges of interpretations of external reality and internal rules. (Pérez Indaverea, 2012). Papadopoulos and Milakasioti argue that:

(...) Gamespace is not static but is transformed into an operational space through the means of interactivity. This space is regarded as a kind of performative space, a 'landscape of performances' acted out by the player as a digital citizen. This characteristic offers the player the possibility to act and develop a more intimate view of the city in personalized terms, such as his own understanding, memory or spatial perception. (Papadopoulos y Malakasioti, 2012, 2).
The image of the city ${ }^{3}$, manipulated digitally in visual media, affects the way it is read and reproduced collectively, and thereby amplifies the understanding of the spaces individuals inhabit through the fusion between real and virtual experiences. (Penix-Tadsen, 2013a). The spatial construction not only involves aspects of visual design, but also takes into account the direct relationship between the character(s) that the player(s) controls through the scenario ${ }^{4}$ constructed in the video game (Dorado Melara, 2017), reflecting the impressions and stereotypes that a particular place could have represented digitally. Penix-Tadsen extends on this notion:

(...) The game world reflects, to an extent, the dynamics of the world in which it is conceived, and ethics do not exist solely within one realm or the other. Appealing to the concept of ludic practical judgment and ludic maturity as accounting for the relativism of interactions between players and nonplayer characters in games. (Penix-Tadsen 2013a).

Other researchers have studied the relationships between city image, urbanism and digital visual media. In particular, Adriana de Souza e Silva and Daniel M. Sutko (2008) have considered how visual technologies give new forms to the interactions between people and public spaces, creating new dynamics of sociability. The authors have also questioned how some hybrid reality games reconfigure and reflect concepts such as community, anonymity, and surveillance in the spaces of the city (de Souza e Silva \& Sutko, 2008). Within urban studies, the relationship between commercial areas and digital media has also led to innovative research into the representation of advertising and the characteristics of urban dynamics (Nelson, 2002). Furthermore, the relationship between commerce and digital spaces has been a fertile field of research for scholars from multiple disciplines, including those who employ comparative, ethnographic, sociological or anthropological approaches. Such research has expanded knowledge on concepts such as consumption, play roles, and didactic activities, among others.

However, it is possible to transfer this debate about the idea of a city or the relationship between this type of structure and the activities that go on within it, to better understand the world of videogames. This paper suggests it is possible to understand the complex structure in the mechanisms used in the development of a videogame to understand the city we play. The representation of Latin American cities as playable scenarios in video games is a useful case study to understand the role of specific formal codes in the consump- 
tion landscape, which for the gamer become not only cultural constructs but also spatial systems (both morphological and typological). The idea that commercial spaces can be interpreted as spaces of consumption, where multiple languages, spatialities and the most in-depth characteristics of the Latin American city are represented, is relatively overlooked in the literature. Nevertheless, categories such as informality and formality, and rethinking of them with technology, have been the subject of scholarly interest, with new research investigating how new forms of communication allow the possibility of new articulations between formal businesses and informal activities. (Chandra, 2017).

Many of these definitions are based on and proposed from concepts analyzed in the light of contemporaneity, in other terms, from the description of the contemporary city and its everyday life cultural practices. Some of these characterizations and conceptualizations are exposed with no particular order in the book: Telecommunications And The City: Electronic Spaces, Urban Places (Graham \& Simon, 2002), opening the debate and relationships between: The 'Invisible Cities' (Batty, 1990); the 'Informational City' (Castells, 1989); the 'City in the Electronic Age' (Harris, 1987); the 'Virtual City' (Martin, 1979); the 'Electronic Cot- tage' (Toffler, 1981); the 'City as Electronic Spaces' (Robin \& Hepworth, 1988); the 'Virtual Community' (Rheingold, 1994); the 'Non-place Urban Realm' (Webber, 1964); or 'Cyberville' (Von Schuber, 1994). This selection only hints at the wealth of new studies that explore the inhabitation of the contemporary city at the height of a postmodern society.

Other academic approaches has dealt with the socio-cultural representation of space in terms of new technologies, social media and new interactions in the virtual space of a postmodern society, including, for example, the Liquid Modernity (Bauman, 2013) and the "Virtual Reality" (Virilo, 1995). The collectiveness of virtual reality as a social intelligence (Lévy, 1998), presenting the ludic experiences and the dialectic between the complex reality and the possible future.

Representations of Latin America in popular culture of the 20th and 21st centuries have been conceived through stereotypes (Roman, 2000), and videogames are no exception. Researchers have already considered the stereotypical categories under which Latin America has been portrayed. From Pitfall! (David Crane -Activision, 1982), the first game that happened within a 2D linear 8bits Latin American scenario, to Call of Duty: Black Ops (Treyarch - Activision, 2010) (See Fig. 1), a game that in

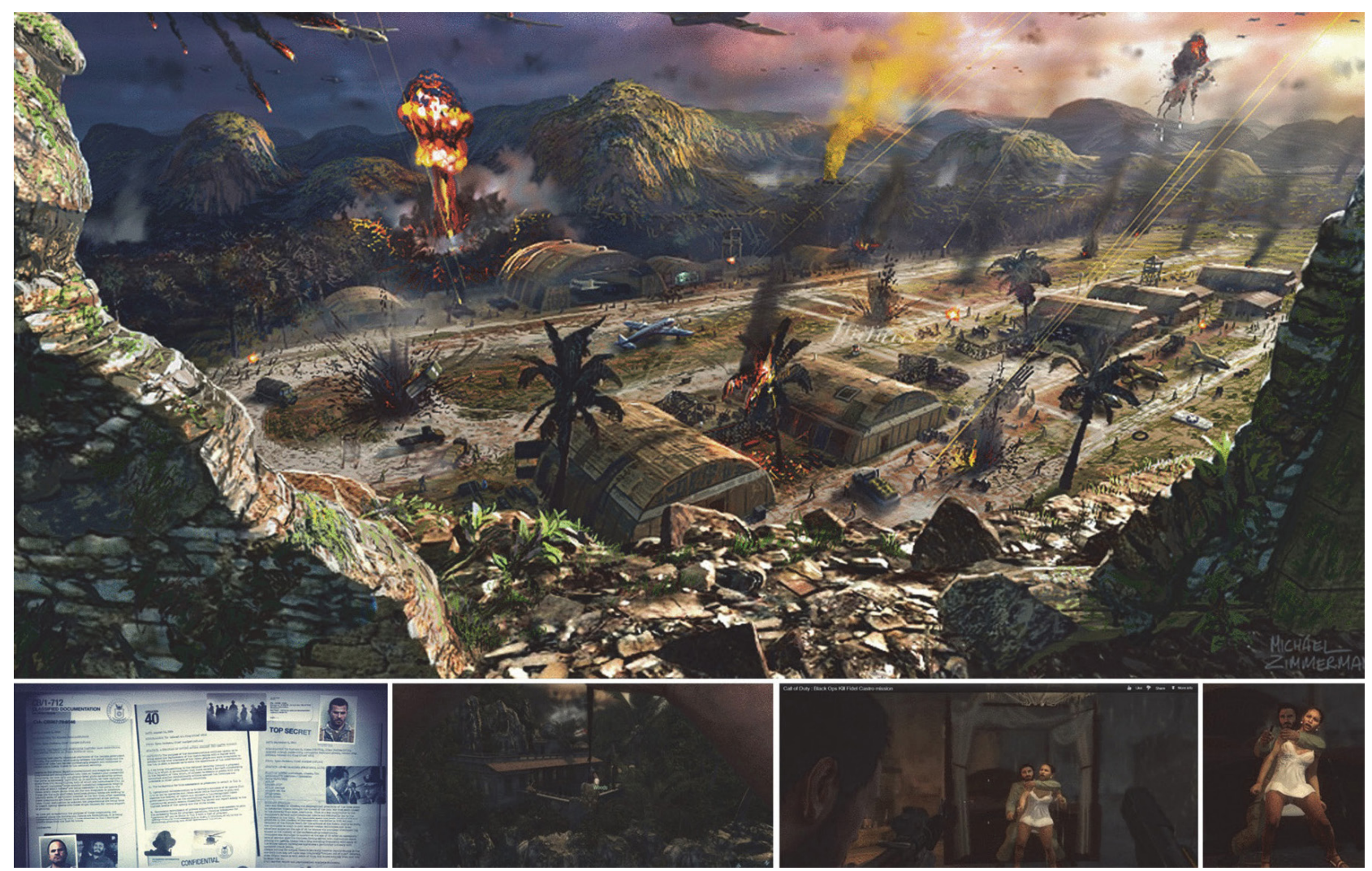

FIGURE 1. TOP: (1) Aerial image of the geographical context in which operation 40 takes place: Bahía de Cochinos, Cuba; within the game CoD: BO. The image shows a landscape characteristic of the Pinar del Rio Province and not the real place (Bay of Pigs). However, it works to recreate its natural features and its topographic condition. DOWN: (From Left to Right) (2) The brief of the mission with conceptual elements: photographs and a description of the place where the mission will be carried out. (3) The entrance to the presidential house of Fidel Castro, which according to the game is presented as a mansion in the middle of a remote and high mountain. (4) / (5) The showdown scene of this mission. However, the exciting part of the action here is the stereotypical representation of the Latin American woman (Cuban in this case), because of her sexualized body image, but also because of her dress. Source: Activision. 
2010 broke records as the entertainment product with the best launch in the history of the video game industry, and where the first mission in the gameplay occurs in Cuba. ${ }^{5}$ This is why researchers like Philip Penix-Tadsen have highlighted the importance of pointing out the incompatibilities between the Latin American aesthetics and representation that appears in videogames and their social realities, since those found in the virtual world do not always reflect the image of Latin America that many people around the globe will recognize. This does not mean that some of those processes or environments pictured and developed in a Latin American narrative cantered videogame do not exist in real life, but, as Penix-Tadsen has argued, the collision between some elements (e.g... informal-formal) and the exaggerated repetitive use of some stereotypes is significant to the way the games are consumed, and this constitutes the central focus of this article.

According to Chávez, there have been different approaches to the study of stereotypes in video games, and he defines three broad categories of videogame narratives set in Latin America: the "Contras" game typology, where the player faces a group in the margin of the law (paramilitaries/militias) in Latin America; the "Tomb Raiders", where fantastic treasures of lost pre-colonial societies are pursued; and the "Mexican Wrestlers", which feature drastic characterizations of racial discrimination and poverty. Another way of approaching the issue has been through models and socio-political factors that have led to the construction of the premise of complete games or sagas, such as the series Tropic (Gathering of Developers, 2001), set on a fictional island of the Caribbean Sea where the player promotes and manages the construction of a dictatorial political system, embroiled in ethical dilemmas concerning corruption and power (Chávez, 2010).

It is in this framework of the representation or characterization of the Latin American city that stereotypical depictions of its landscape are promoted. The experience and the gameplay interact with narrative scenarios that immerse the player in a space loaded with symbols. As Di Felice argues, "(...) The experience of inhabiting the city transforms by following the new relations that the subject creates with space. The observation that this one does of the territory, across the technological mediation, is dynamic, and it portrays, in turn, the independence that the landscape has with the inhabitant" (Di Felice, 2012). This observation prompts a fundamental reconsideration of the role of urban representation in videogames, its impact on the way gamers perceive the city, and the interdependent relationship between observation and territory.

Di Felice expands upon his definition of the urban landscape in Paisajes Posurbanos, El fin de la Experiencia urbana y las Formas Comunicativas del Habitar, attesting that:

the contemporary urban landscape, constructed and represented by information and communication technologies, makes inhabiting an experience of continuous movement, which goes beyond the physical space and makes to create and disseminate emerging social practices, conceived from a need to communicate and interact with a technologically reproduced environment (Di Felice, 2012)

Di Felice and other scholars have proposed that it is in the interaction with images or collection of images within digital environments, that players (citizens) can experience or inhabit new or familiar urban spaces from positions that may or may not be able to reach in real life. More broadly, the concept of reality goes through a sieve of different interpretations in the world of video games, as players enjoy new experiences in their avatar or virtual role. It is then, from the position of the player that we should try to approach the complexity of this reality, or as Di Felice puts it, "(...) this view of the world multiplies the images of reality, influencing its perception" (Di Felice, 2012).

Recalling the position Nicholas Negroponte takes in Being Digital (1995) is equally significant: that the physical world does not cease to exist, but rather merges with the digital world, promoting new ways of interacting in it or with it. In other words, the landscape that is established in a videogame is not real, but it does provide a "reality" or sorts, with its own rules and unique representations that aid both the narrative construction and the ludic experience. As Di Felice suggests, it is an independent space that establishes a new relationship between the player and the landscape:

(...) The virtual spaces represent an imaginary inhabiting that can end up being opposite to the real life, but true in its virtual condition; (...) In this sense, digitized spaces achieve independence from places, providing a different relationship between individual and territory, which shows new ways of socializing in fluid urban environments, manipulated and perceived from an immersive experience capable of creating new spatial realities (Di Felice, 2012)

The representation and stereotyping of the Latin American city became the working route to understand the spaces of the city that are proposed in the videogame. However, it is also necessary to approach the conceptual basis of the stereotypes with a reading of multidisciplinary scholars in order to define categories of analysis in the cases explored here. This challenge proposed as part of the work within the Department of Architecture of the Universidad de Los Andes, Colombia, began as a research project with undergraduate students based on the use of videogames as a tool to understand cities. The first approaches to these topics came in the form of debates within the classrooms that brought up student interests about working methods that aided them in interpreting historical spaces, or landscapes of some relevant moments in history, but also paradigmatic cases found in cultural productions such as painting, literature, cinema, and video games. Quickly, the first experiments were producing interesting results. For example, in the first experiments students played The Order 1886 (Ready at Dawn - SCE 
Santa Monica Studio, 2015), to be able to understand the city of London in its Victorian era at the end of the 19th century, not only because of the stylistic characterization or the visualization of some aspects close to our discipline, but actually "enter and go through" directly on the in-game open maps of London, allowed to go in-depth into the scenarios, and connect with other cultural products: books of history, novels of Charles Dickens and Sir Arthur Conon Doyle, among others.

This last aspect turned out to be extremely important since it was not a taxonomic understanding of historical reality, nor a diachronic or synchronic revision of the historiography of the city as an object of study. In architectural schools, especially those in Latin America, the teaching of architecture and urban history is often presented as a separation of elements for the understanding of a complex totality. As a result the complexity behind any case of study ends in a simplification of isolated topics or in the compression of concepts and historical processes into a pedagogical "pill" that students should elaborate further. For example, on the study of a specific building of the Baroque period explained in a class, should be extensive and even paradigmatic for every Baroque building or city of the $17^{\text {th }}$ Century. Important challenging questions surrounding the sequence of historical events, political, economic-models, other cultural connections or technical situations, were always left aside in order to address a discussion of the most synthetic aspects of buildings or cities.

However, the possibility of using the videogame, especially AAA $^{6}$ class games, as a mechanism for understanding these realities, (and as learning-research tools, opens the door to greater enthusiasm amongst students, who can instead understand a more comprehensive spatial whole, full of codes and formal values, atmospheres and materialities, that allows the player (or student) to engage in direct interactive immersion and to be able to travel and visit the eras and themes previously only discussed theoretical. In other words, "visiting" London at the end of the 19th century, "going through" the gloomy and cold alleyways of Whitechapel, is no longer limited to the terrain of images and imagery found in paintings or literature, but can be visited, understood, and even measured through video games. It is possible for a student to look or enter into a historical building that a professor is trying to explain as paradigmatic milestone of a particular historical moment. (See Fig. 2)

It is important to recognize the videogame as an object of study and understand its playful value within the position of disciplinary knowledge in order to promote a broad and retroactive debate on education and teaching about the city.

\section{STEREOTYPES AND LATIN-AMERICAN LANDSCAPES: STEREOSCAPES}

Stereotypes have been studied in many disciplines with special attention in the social sciences. In a recent review of contributions to the debate around stereotypes, the range of work tended to focus on the approximations to this concept from notions close to the contemporary cultural practices. These notions allowed the construction of a baseline of work and therefore the organization of its structural characterization. Stereotypes are a mechanism in which the patterns and associations of what is perceived by any person or groups of persons are compared with their real-life habits and ways of being. It is due to stereotypes or categories, generated by subjects that anybody can interact and comprehend any particular context, but it is also the reason why some of these identifications are misunderstood or generalized. To begin to understand the generation of stereotypes according to Kassin, Fein \& Markus (2010), first there must be a thorough appreciation of the concepts of endogroups and exogroups. Endogroups are those to which a subject belongs or identifies; an affiliation related to sex, race, culture, or other characteristics. Exogroups, meanwhile, are groups to which the subject is foreign but to which they nevertheless directly or indirectly interact with.

It is in these interactions that stereotypes generate differences or equalities recognized among identities, allowing the contrast between who is integrated or not in a group. These categories are maintained or strengthened depending on the number of interactions but also based on the culture and experience of the subject. Moreover, these categories or stereotypes are generated by unconscious behaviours that are established in encounters with exogroups; essentially, the stereotype can be reinforced by practices on the part of the person who behaviours in ways that correlate to those expectations (Bergh, Chen \& Burrows, 1996).

Stereotypes have a political, economic and historical burden that extends across time. The origin of cultural stereotypes is generated historically by a long-lasting background of retroactive interactions cycles. In the case of the peripheries, or Global South countries, characterizations are recurrent and maintained by a continuous loop of unconscious or conscious use of stereotypes. In the deliberate characterization, there is a greater tendency for the information of stereotypes to have a real basis, but both are generated through human interactions between society and a place that makes it endure. Stereotypes can also produce a threatening characteristic for a particular culture (Tsukamoto \& Fiske, 2017). This characterization occurs from two factors: perceived competitiveness and social relations within the group. In the case of competitiveness, the groups with greater poverty are perceived as less competent; this is the case for some of periphery countries. A culture where more friendly and cooperative social relationships are prevalent generates a threatening perception for others (Tsukamoto \& Fiske, 2017).

In the case of the so-called periphery or Global South countries, stereotypes have political, social and economic strains caused by the history of repression and conquest. A cultural representation of underdevelopment, poverty, corruption, violence and disorder that takes place in a context that is rich in natural scenarios inspires a series of 

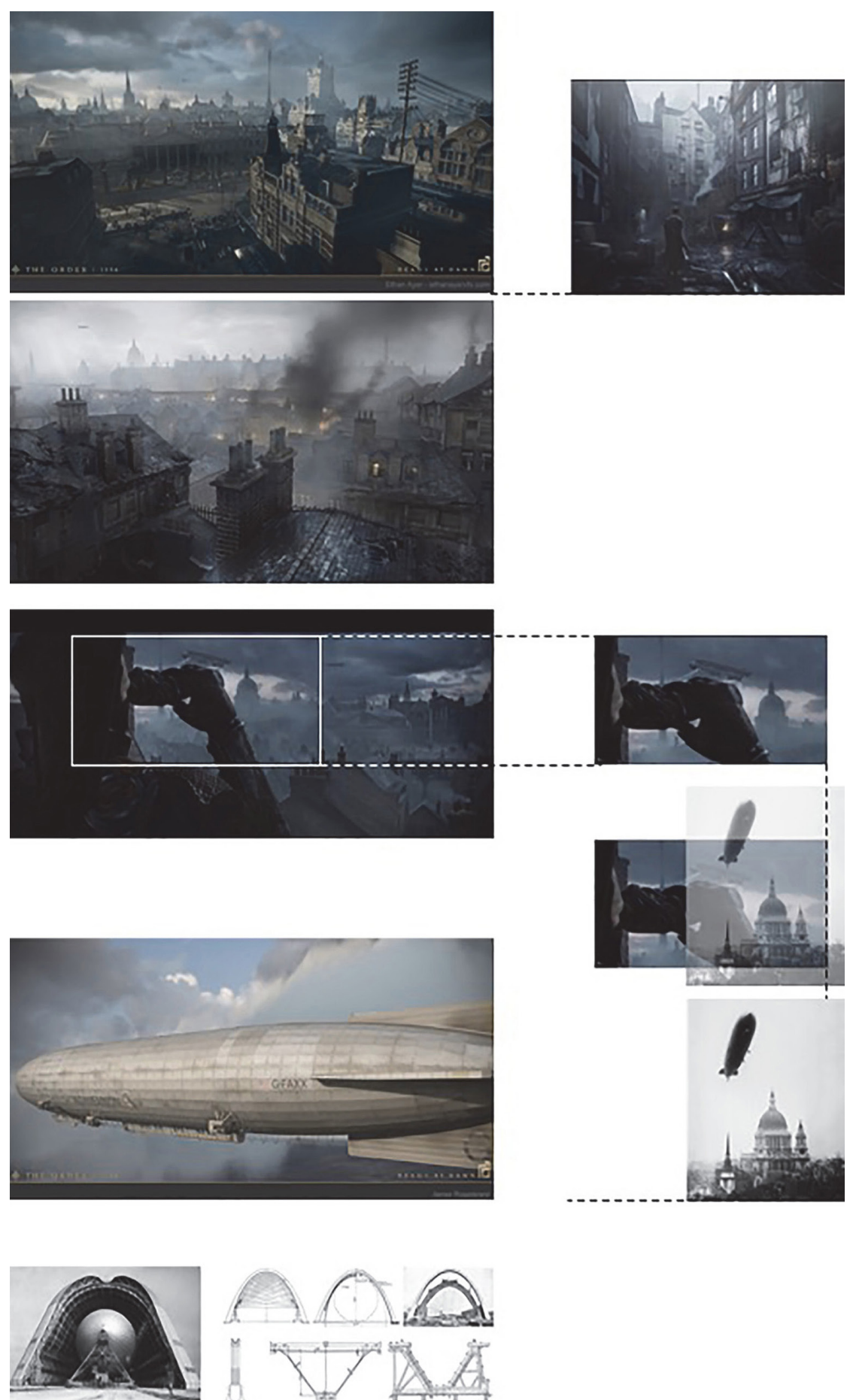

Figure 2. Analytical work in DigitalScapes research program, Department of Architecture, Universidad de Los Andes, for the videogame: The Order 1886 (Ready at Dawn - SCE Santa Monica Studio, 2015). From top to bottom, left to right: (1) Initial scene of London at the end of $19^{\text {th }}$ Century. (2) Tour through the streets of the Victorian city in East of London; (3) East London from the rooftop; (4) The observation from the distance of one of the main characters about the context of London; (5) Screen capture of the previous image to the St Paul's Cathedral (Zeppelin on the side, by that moment this type of aircraft did not fly over London); (6) Superimposition of the real image of the Graf Zeppelin over St Paul's Cathedral, London, 1930 with image 5; (7) image of one of the missions in the game TO:1886 inside one of the Zeppelins; (8) real image of the Graf Zeppelin over St Paul's Cathedral, London,

1930; (9-10) hangars or brutalist architecture of the early twentieth century where Zeppelins were manufactured or repaired / architecture drawings of the hangars. Sources: (1-7) The Order 1886 (Ready at Dawn - SCE Santa Monica Studio, 2015) videogame captures; (6,8) The National Archives, AIR 11/237 (retrieved from: https://history.blog.gov.uk/2015/01/19/air-raid-casualties-in-the-

first-world-war/; (9-10) Polano, Sergio. (2016) “Gli Ultimi Nidi Delle Aeronvi”, Revista Casabella 867 (n.11 / 2016), p. 3-13. 
visual stereotypes which ignores the deeper multi-realities that underpin it.

Some of these generalized images or stereotypes are created from the "first world" or developed countries. These cultures, with their different perspectives, are the foundations on which a homogenized qualification of others is built. This interaction with exogroups generates the phenomenon of "priming" that refers to the extension of some cultural structures thru the transference of knowledge between subjects (Bargh, Chen \& Burrows, 1996).

This is how the picturesque image of the peripheral countries are usually portrayed with preconceptions or perspectives. For this study, the emphasis is on the representations of the Latin American city with a mind to revising the construction of landscape stereotypes, or what we have called "stereoscapes". Videogames set in Latin America involve an accumulation of metaphors that move away from reality but that work for narrative purposes (Penix-Tadsen, 2016). It is very likely that any representation of the city, regardless of its cultural, political, economic, or social background, generally can be stereotyped to build a synthesis of images that evoke notions of these places but that do not necessarily represent the deeper characteristics of their real-world contexts. However, for this article, the interest is to dismantle, organize, and even establish the organization of elements founded in the Latin American city portrayed in the games selected.

By synthesizing Chávez (2010) and the models of the Contras, Tomb Raiders or Mexican Wrestlers, it is possible to see the Latin American city, no matter which actual city or historical moment, as a lush landscape in natural values, vegetation, fauna, topography, a place very rich in resources but little "developed". On the other hand, the city is also economically poor, with favelas as its preponderant morphology or "ranchos" as its primary architectural typology. Equally, from the sociological point of view, the Latin American city is characterized by corrupt political classes, criminal gangs, prostitution and extreme poverty. These stereoscapes are based on the most reductionist, selective and generalized image of the Latin American city to build a fantastic narrative for the videogame.

A comparison of recent video games that depict Brazil provides a good introduction to the debates surrounding the juxtaposing stereotypes of the Latin American city. Papo y Yo (Minority Media Inc, 2012) is a game set in a $3 \mathrm{D}$ environment in Rio de Janeiro with a narrative in the third person, developed as an independent game. Papo $y$ $Y o$ also managed to reach the wider market of the more mainstream video game platforms. It has a subtle aesthetic that recognizes the stereotyped landscape of the favelas while also conceiving them as a large digital playground, turning the urban stage into a playable infrastructure. Call of Duty: Ghost (Infinity Ward - Activision, 2013), considered an AAA category video game, much like its predecessors Call of Duty games, is a space-time narrative that depicts Rio de Janeiro as a favela, though as a much more violent playable environment. However, it is in the third person shooter videogame Max Payne 3 (Rockstar Games, 2012) where the most problematic cases of stereoscapes occur. In the game, the main character carries out a mission in the detailed violent favelas of Sao Paolo. Critiques of the videogame from Latin-American players (especially Brazilians), have shown that the landscapes in the game scenarios portray a city quite different to Sao Paolo, and much closer to Rio de Janeiro. The use of some references, such as vegetation (palms, rhizomes, among others), tropical attires, and the entire material world, is more reminiscent of Carioca society rather than the local Paulista aesthetic. (Fig. 3)

The series of games for PlayStation entitled Uncharted (Naughty Dog, 2007-2017), propose action narratives and adventures that take the player through different locations around the world. While Uncharted: Drake's Fortune (Naughty Dog, 2007) and Uncharted 3: Drake's Deception (Naughty Dog, 2011) both feature scenarios set in some parts of Latin America, it is in the third edition that this article focuses, particularly the display and narrative development of the landscape and its stereotypes in the representation of the Latin American city, in this case the historical city of Cartagena, Colombia (See Fig. 4). Uncharted 4: A Thief's End (Naughty Dog, 2016), does not occur only in Latin America. ${ }^{7}$ It has also connections to other regions of the southern hemisphere, including Africa, which we will include in this article as an extension of the findings and not as a comparative or control case . (See Fig. 5).

Uncharted 3: Drake's Deception [U3:DD] (Naughty Dog, 2011), have multiple approaches to the definition and "spatial" construction of the Latin American landscape, pre-empt two of the main debates of this article. Firstly, there is its narrative construction. Nathan Drake [Drake], the game's protagonist, remembers part of his early childhood while walking and climbing the buildings of the ancient Caribbean city of Cartagena (Cartagena de Indias $^{8}$ ) in search of a legacy left by his ancestors. This temporal deconstruction in the narrative is significant because its forefronts a compelling spacetime vision that helps focus the central argument of this article: the digital construction of the Latin American city. Secondly, and from the disciplinary point of view, it is important to open up the spatial approach for the extreme wealth of knowledge in the fields of history, architecture, and urban studies. The commercial spaces or landscapes of consumption and its representation in the videogame as a case study, became the trigger a series of interdisciplinary debates about the representation of the landscape in a digital world, with layers of stereotypical images.

\section{METHODOLOGY: A JOURNEY THROUGH SERIAL VISIONS}

In the U3:DD game's plot, players follow Drake and through several urban and architectural spaces in an experiential "virtual" journey through Cartagena de Indias, 

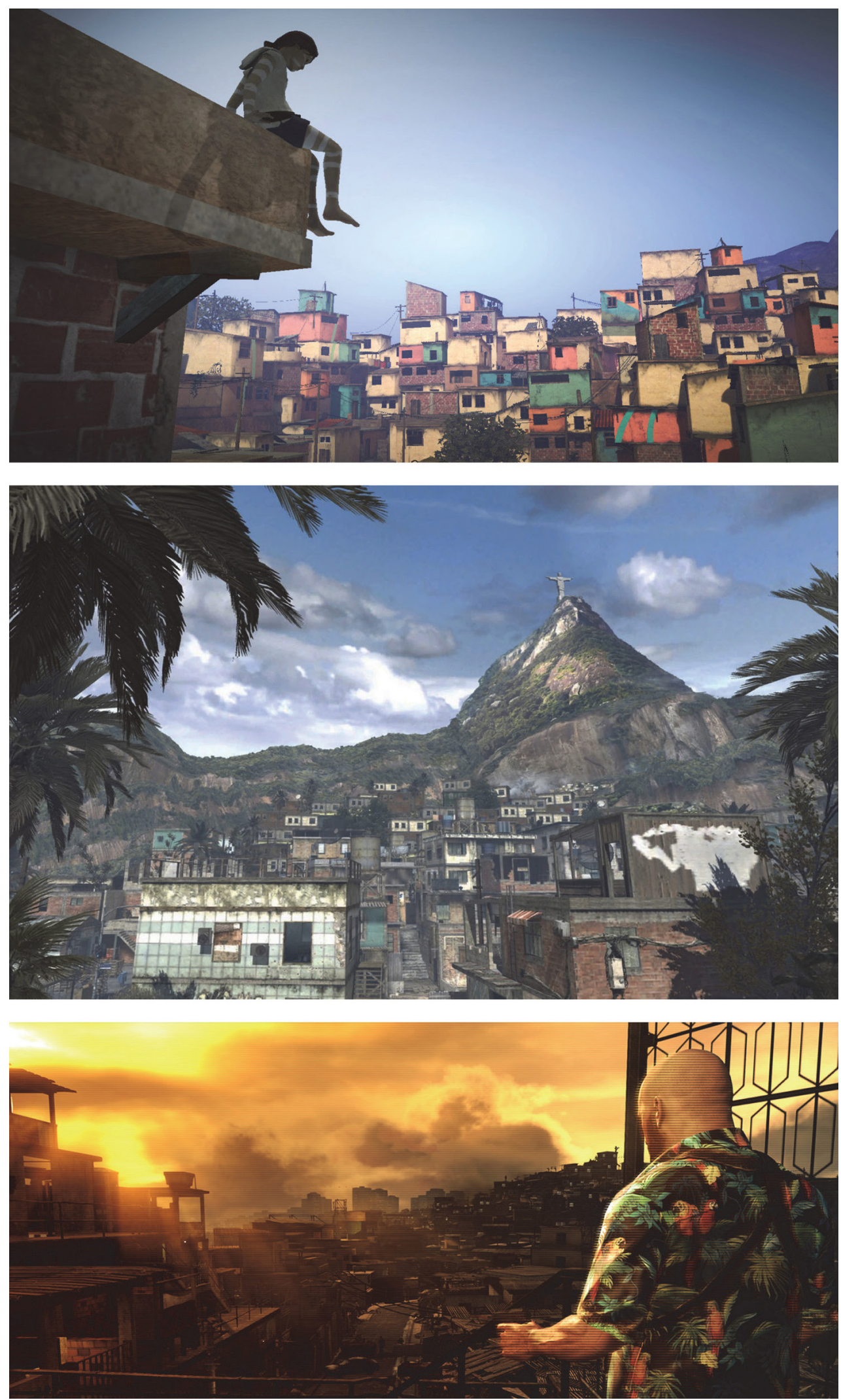

Figure 3. From top to bottom: (1) Rio de Janeiro Portraited in Papo y Yo (Minority Media Inc, 2012); (2) Rio de Janeiro represented in Call of Duty: Black Ops (Treyarch - Activision, 2010); (3) Sao Paolo favelas in Max Payne 3 (Rockstar Games, 2012). Sources: (1) Minority Media Inc. (2-3) Activision. 


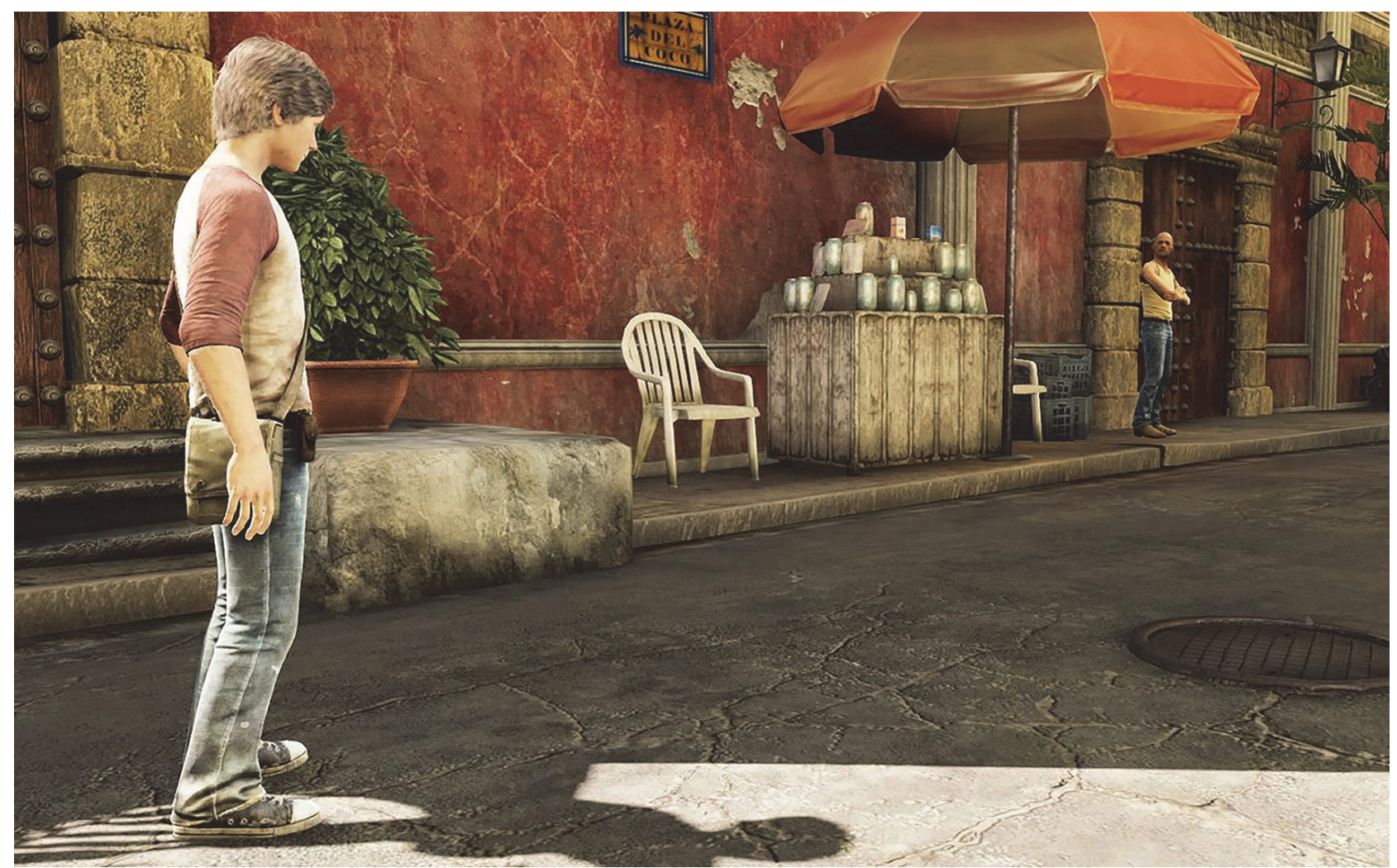

FiguRE 4. Screenshot of Cartagena in Uncharted 3: Drake's Deception. Source: (Naughty Dog, 2011).

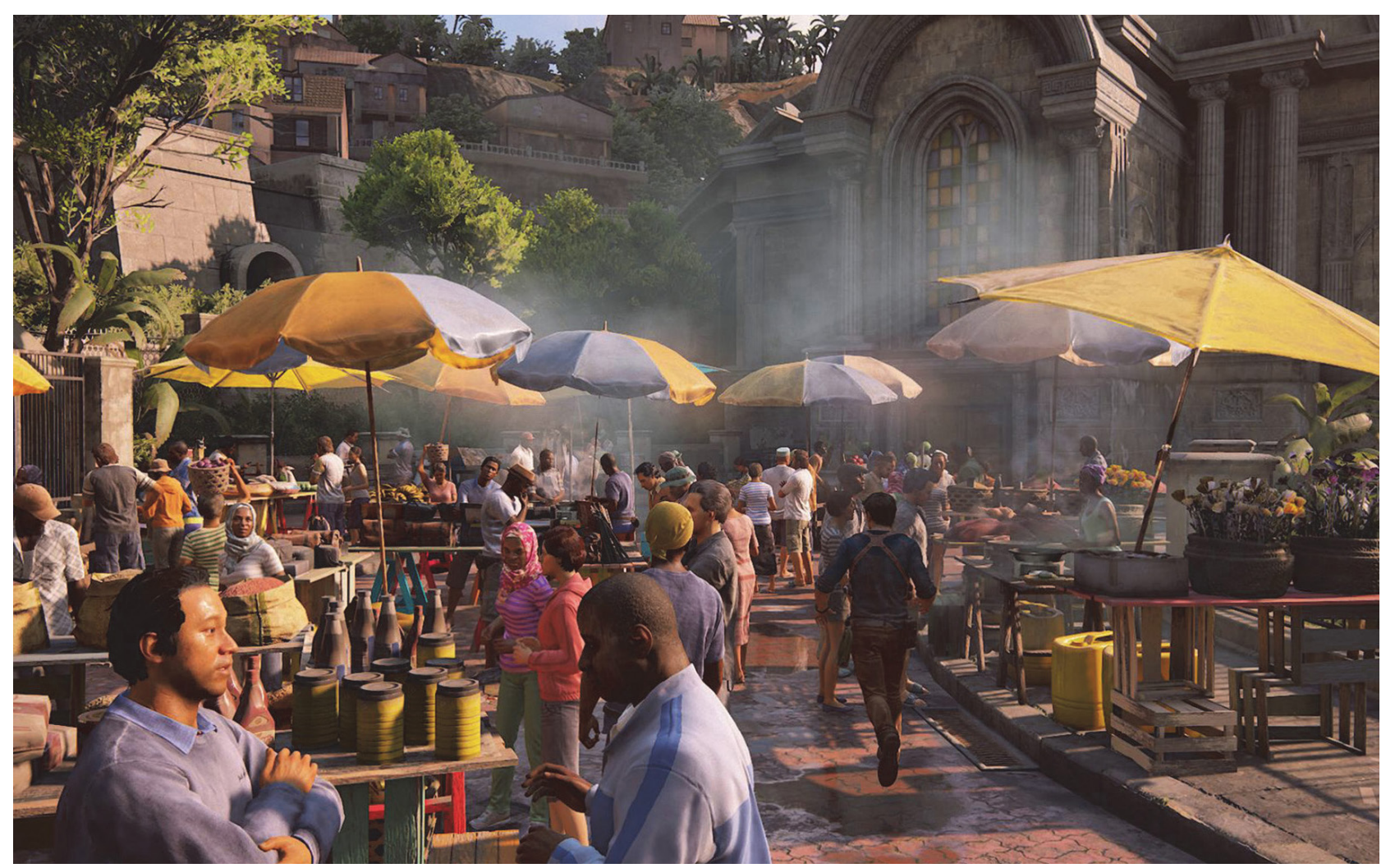

Figure 5. Screenshot of the walkthrough Madagascar market mission in Uncharted 4: A Thief's End. Source:(Naughty Dog, 2016). 
Colombia, as he searches for a secret treasure left by a famous pirate and predecessor, Sir Francis Drake. The character must make a series of reconnaissance operations in the urban landscape as digital journeys through the historical city townscape, a concept used by Gordon Cullen in his famous text The Concise Townscape (1995). The author also presents an analytical position on the city from the use of the senses, particularly emphasizing the use of the eye as the most important and sensible organ. To achieve this sensorial construction that leads to a perception of space, the author proposes the serial vision as the method to achieve rigor in the analysis through a collection of images.

This idea of a collection of images that produce knowledge emerging from the interaction with digital environments is reinforced by Di Felice who points out that: "(...) An interaction is created, this way, between subject and scenery that goes beyond the visual relations, since an inhabitant experience is created of immersion capable of altering the space employing one interface" (2012).

This qualitative approach on how to interact with the city through the understanding of the visual form of the objects, urban morphology, and its architectural typologies, works to put place Drake in direct conflict with the narrative. While it is true that the game proposes a series of steps to follow to accomplish the tasks assigned and advance through the game's stages the gameplay of this part of the game allows players to make detours through the city and to explore the spaces in it, unleashing a visual and spatial rich scenario.

One observation of this imaginary where Cartagena is constructed, is related to the narratorial aspect, or more precisely the linear rupture (space-time deconstruction, remembering the literary deconstruction or the possibility of using historiographic tools such as diachrony-synchrony (Braudel, 1990)). Drake travels to Cartagena from his memory of childhood as an escape (or semi-conscious dream) in search of his past. In this sense, Drake's interpretation of Cartagena comes to us through the filter of his possible imaginary or memories of this city, a perspective which is in conflict with the "reality" of the city. This exchange can also offer us a series of new codifications from the background of the character (whether in relation to age, culture, gender, or other characteristics).

For this research, regardless of the narrative construction (taken as they are from the memories of a fictional character) or the knowledge of the team that developed the game, it is the representation of the historic Latin American city that is the object of study here. The hermeneutics or interpretation of this representation from the gameplay, the ability to make gamers travel to a past not very distant but in a walled city of the sixteenth century in our context, is the core of our proposal.

Methodologically this study focused on the use of U3:DD on tours through the semi-open map of Cartagena, to collide all the findings. These tours have two ap- proaches: one centers on the relationship between the narrative and the interaction with the gameplay scenario, so that it establishes a necessary thread for understanding what the developers want to suggest to players. The second approach is to makes digital detours in non-linear routes, apart from the main exercises or central tasks of the game, in search of surprises in the way of representing the digital scenario of the Latin American historic urban landscape.

In both cases, linear or free random explorative journeys are predetermined paths (have a beginning and an end), meaning that the walkthroughs and the detours work with the same structure of analysis offered by Cullen. The starting point are the journeys already proposed by the game, and from there is a rigorous capture of images from the gameplay (the author uses hand drawings). These images are taken severely along the trip using a timeframe, contrasting with the method of distance proposed by Cullen. For a video game, the idea of distance is falsified by the digital environment. These images constitute the serial vision of a journey close to a cinematographic collection, which later is analysed independently (image by image) and a continuous mode (transversal elements, repetitive elements, etc.), interpreting, conceptualizing, and organizing them.

For this research, each of the game sessions was logged to document the results and record the exact moment they were discovered, creating a graphic memoir along with the screen captures in the walkthroughs or detours 9 . This made it possible for the whole team to review this data, take specific notes, and generate debates around them. This documentation, very close to the field journals used in the social sciences, allowed us to obtain a broad register and select the topics presented in this article. These issues question in principle an idea of inhabiting the digital world but also feeds the representation of stereotypes in the Latin American city.

Authors like Maurizio Unali have categorized the ways that the digital worlds can be analysed, understood, approached and inhabited. In Atlante Dell'Abitare Virtuale. Il Disegno della Città Virtuale, fra Riserca e Didattica (2014), the author displays a robust characterization of the different ways in which the city has been represented within digital environments. These environments are not exclusive to videogames, but it is in the latter that the idea of habitable worlds or cities have developed with higher intensity. Unali organizes the text around a review of case studies, three types of spatialities or ways of inhabiting these digital environments: The representative-instrumental space, the formativecreative space, and finally, the media-informative space. Although it is not exclusive of one another in the representability of the environments, this approach encourages an appropriate degree of organization in order to discuss the findings.

These spatialities made it easier to classify the spatial images (landscapes) selected in the gameplays into the following characterizations: Formality vs. Informal- 
ity, as the representation in the debate of stereotypes. The presentation of commercial structures in the videogame, not only as built form or urban spaces dedicated to a specific commercial activity, but as places where the interaction between buyers and sellers occurs; spatial formats where different types of sales are manifested, and the use of the surfaces (ground, walls, among others) as the most notorious interactions within the context of where the game takes place. Finally, the analysis of the consumption spatiality represented in the interaction with the objects, the organization of the products within the commercial structures, the implicit materiality in this type of spaces and publicity as a mechanism or link between the specific communication of objects or uses and the commercial landscape in its entirety, this last narrative aspect within the videogame is presented as Di Felice already proposes: “(...) the publicity fused with architectural elements transports the observer towards a "multiplication of experiences in the landscape" (2012).

\section{FINDINGS IN THE WALKTHROUGHS AND DETOURS: UNCHARTED 3: DRAKE'S DECEPTION}

The third version of the saga Uncharted saga (Naughty Dog, 2007-2017) takes place in an "imagined" city of Cartagena, with very similar characteristics to the real historic walled city, even though the characters and the soundtrack transport us to a Spanish rather than Colombian atmosphere. The public space is recreated with a mix of informal markets and colonial architecture. However, the unmistakable military walls that enclose the old city are not shown. The daily life of the inhabitants is represented with actors that resemble street sellers and a scenario of spontaneity, or a "kindness" very close to the stereotypical Caribbean way of life. At the very beginning of Chapter 2, voices of the inhabitants and local traders are a part of the gamer experience. The sellers are heard hawking their tropical fruits and other goods like empanadas or arepas (corn bread).

The opposition between formality and informality can be seen in the opening scene of the game set in a London, England bar, where clients sit comfortably having a drink. The punters are aware of the business conditions through a notice that explicitly indicates that no credit is given, and the viewer contrasts this image to the scene in which a twenty years younger Drake appears walking through a market square in the middle of a road in Cartagena, in the midst of vendors and buyers, who offer products in the open air, without any apparent order, establishing themselves in a spontaneous trade relations where prices are not regulated. This, arguably, is a reference to the typical informality of Latin American commerce: no prices are shown, and the transaction typically is the result of haggling.

In Colombia, the so-called informal economy is a real phenomenon, since people who have fewer labour oppor- tunities and less chance of fixed income or social security find ways to survive independently. These statistics are not featured in the official macro-economic reports. Among the activities carried out under this modality are the itinerant sales of fruits, vegetables, meats, and handcrafted goods made with products from the region (necklaces, bracelets, backpacks, among others). In Colombia, according to the recent economic study (Jul/23/2018) from the UN-International Labour Organization (ILO, 2018), those working in informal or vulnerable labour conditions are close to $60 \%{ }^{10}$. Its size could be close to $30 \%$ of the gross domestic product as measured by the national government. The operators of the informal markets, national or municipal, do not follow legal regulations; in fact, their competitive advantages are supported in the evasion of taxes. The informal trade expands every day as part of the urban landscape of our cities, and as a reality that cannot be hidden. Uncharted 3 incorporates this real-life economic context as a playable element of the game.

The commercial structures are shown in the game from the interaction between the seller and the buyer, in a relaxed, informal environment, sometimes in stationary booths and others in an itinerant way, where the merchants use the public space as counters for their produce. It becomes evident how the seller takes the street to expose articles offered to the visitors. A practice that leads to pedestrians stop-by and makes interaction with sellers. (See Fig. 6)

The commercial spatiality of the Latin American city is reflected in the game through its narrow streets invaded by stationary and itinerant vendors, in which many cars do not circulate and are mainly travelled by people, who enjoy walking and getting to know charming places, like the Church of San Pedro Claver, the Aduana Square and finally the commercial corridors and arcades, among other historic buildings that give the city its shape and character. There is a sense of engagement to appropriate the Cartagena architectural heritage into the set design that gives an urban configuration that works in the narrative purposes of the game.

These configurations planned and designed reflect somehow the society that inhabits it. From this perspective, space does not exist in the absolute, but instead relatively, as a result of social interpretations. According to Richard Sennett, space reproduces the order of the values of a society and the social classes among other structural elements. Sennett comments that: "(...) the relationship between body and space, its manifestations and problems, have found expression in architecture and urban planning in cities" (1990). In the video game, commercial spatiality manifests itself from the Latin American stereotype of the disorder of merchants and the bargaining of prices. In Uncharted 3 , some of these stereotypical images are part of the Colombian characterization. For example, the decayed Renault 4 vehicle, the Rimax chairs and the plastic food baskets are some of the most iconic components of every Colombian city; they are not used as a random 


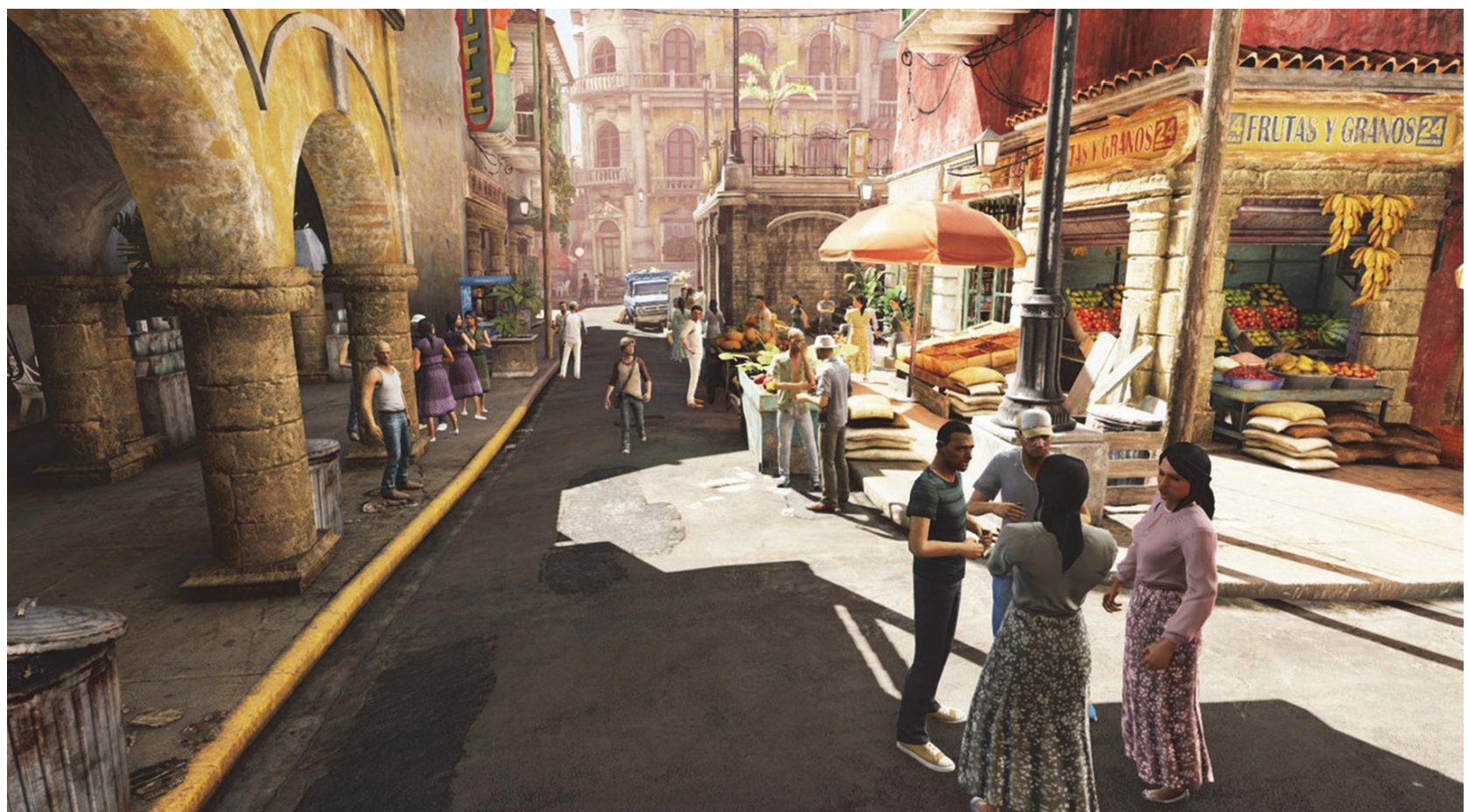

Figure 6. Commercial street environment in Cartagena. Uncharted 3: Drake’s Deception. Source: (Naughty Dog, 2011).

element in the space, since they have a settled symbolic value, locating the player in the urban landscape immediately. (See Fig. 7).

The Rimax chair is presented in different parts of the city, also in different states or arrangements. This object has been used in other videogames whose narrative occurs in Latin-American cities. Is a repetitive element that have become a main characteristic in the construction of informal digital environments (e.g. the Peruvian town of Kuwaq Yaku in Shadow of the Tomb Raider, Square Enix \& Eidos Montreal, 2018). Moreover, the use of the Renault 4 vehicle as one of the most popular cars in Colombia back in the 70's, produce a sort of a national identity. These two symbolic elements enhance the atmosphere but also the narrative of the virtual Cartagena. It is in this argument that the stereotypes produce a certain homogenization of the most relevant cultural values. However, there are some specific and punctual elements that creates a sense of specificity. From connections with Gabriel García Márquez as a subtle element (yellow butterflies) or even more explicit such the use of a specific accent or vocabulary from the street vendors, produces a scenario that moves from generic to specific.

The materiality of the buildings and the public space that serves as the setting for the game does not correspond with the reality of the city; the constructions in a state of abandonment, deterioration, and dirt are appropriated from the conditions of Havana, Cuba. These characteristics were part of the conceptual art in developing of the game since the very first images in the creative process showed a Cartagena with the caption: "Plaza de la Habana" ("Habana Square") instead of Plaza de la Aduana (Aduana Square), the transferring and homogenized image of the cities related to the Caribbean sea, heading the discussion into the narrative. Some of the architectural and urban spaces correspond to real life logic. The objects used in terms of the playable scenarios also connect with the historical city, but their materiality is portrayed in a different way. (See Fig. 8).

Advertising is part of the urban landscape and allows cities to generate new messages, knowledge, and interre-
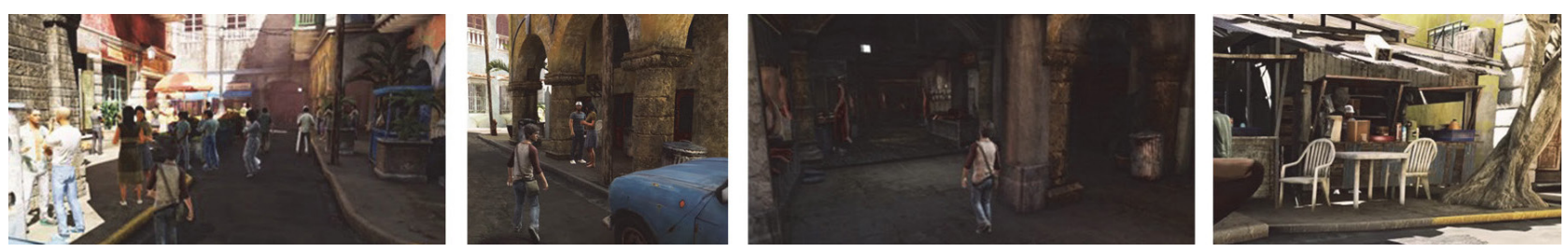

FiguRE 7. From left: Screenshots in Chapter 2: Uncharted 3: Drake's Deception analyzing the sequences of images and the exploration of the consumption spaces and objects related. Source: (Naughty Dog, 2011). 


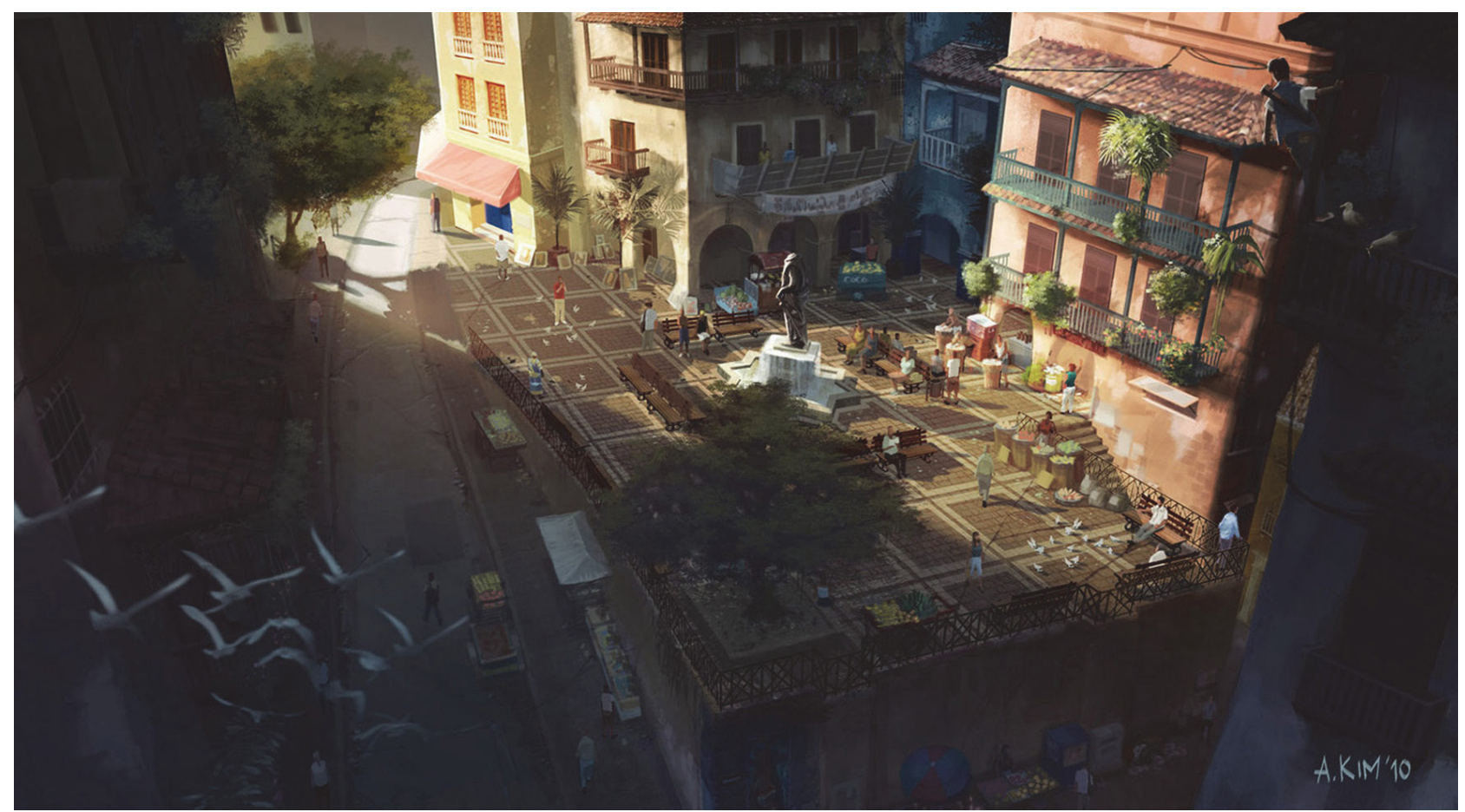

Figure 8. Conceptual art of the Plaza de la Habana (Cuba, instead Plaza de la Aduana, Cartagena), created by the artist Andrew Kim as part of the conceptual team for the recreation of Cartagena in Uncharted 3: Drake's Deception. Source: Andrew Kim Art (http://www.andrewkimart.com/\#/uncharted-3/).

lations among those who inhabit it. Advertising has created links between the architectural language and the perception of those who observe it. In the video game, advertising has a narrative purpose but also works as a communicative method that develops two characteristics. On the one hand, the superimposition of advertising onto the very materiality of buildings, works not unlike communicative "tattoos". In virtual environments, materiality is assigned by images or digital parameters: the rock material is attributed to the model to represent weight, age or certain vernacularity; advertising works as a material object that indicates uses or functions (commercial) necessary for the setting of the playable space but also to drive the plot of the game. On the other hand, the use of logotypes and fictional brands are represented in the game with a visual language that speaks of a stereotyped characterization of the Latin American city. Recalling Unali (et al., 2014), the role of advertising in this video game is classified within the idea of representative-communicative space, conferring additional narrative values to the scenario, providing a particular non-historical look, and fitting more to a postmodern context that is linked to the generation of players familiar with Uncharted 3. As Robert Venturi, Denise Scott-Brown \& Steven Izenour argue in Learning from La Vegas (1972), the representation of monuments is not shaped by its architectural characterization, or its urban value or its historical-cultural importance, but by its ability to represent a message and communicate. The Cloister of Santo Domingo is a church and at the same time a photocopying centre; the Church of
San Pedro Claver is a monument where keys are made. It is in this mixture or collision of symbols where the commercial message surfaces as another way of stereotyping the Latin American city. (See Fig. 9)

The Aduana Square in Cartagena, since its foundation was destined to be a city hall as a posthumous tribute to the illustrious former president of the Republic, Rafael Nuñez. Over the years the space has been transformed into something purely commercial. It went from being a symbolic and honoured place where government, civic and democratic activities were practiced, to an informal sales space with street vendors and prostitution. This environment is captured by the videogame and is one the most recognizable spaces in the digital city. (See Fig. 10).

The Church of San Pedro Claver is represented as an old, abandoned building, without any importance for the city and implanted in an alley. However, in real life, this religious site is of utmost importance for the city, because of its historical significance, as well as architectural heritage and cultural value. The church was declared a National Monument in 1995 by National Government Decree 1911. The architectural structure was built at the beginning of the 17 th century to become the headquarters of the first school of the Company of Jesus in America. The building served as the headquarters of the major San Carlos Hospital at the service of the Spanish army. After independence, it became the San Juan de Dios charity hospital. In the opposite sector of the Republican wing of the building is the neoclassical architectural design that was used in 

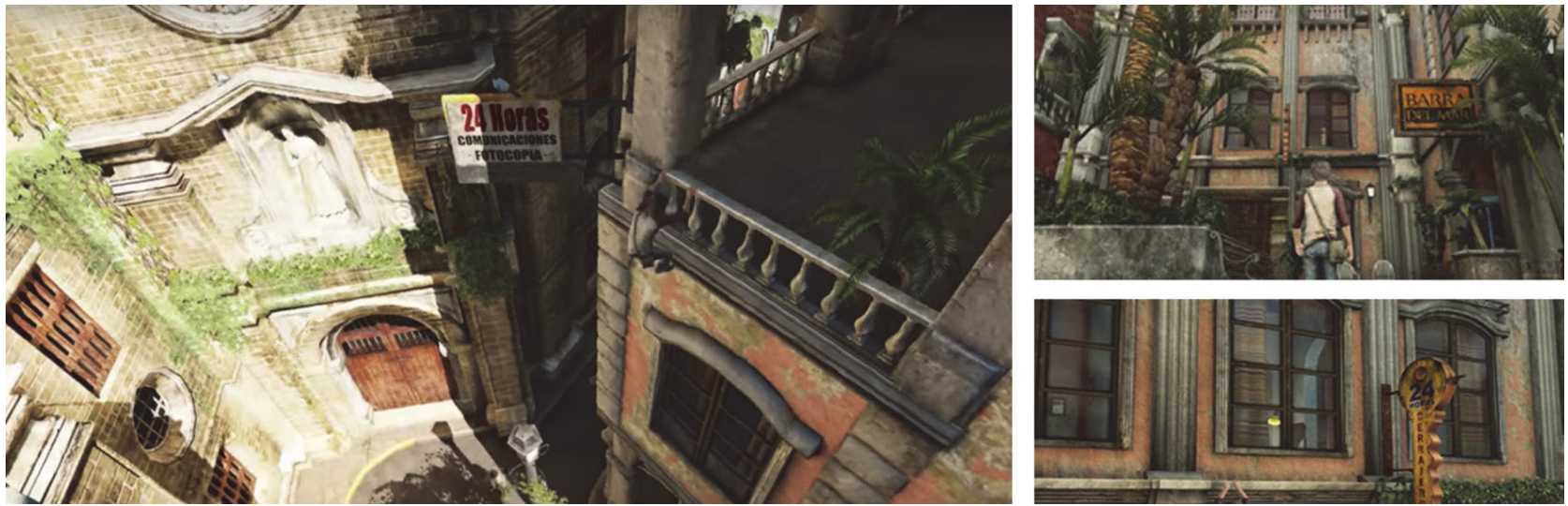

FIGURE 9. Left: The superimposition of the mixed church/photocopies centre, reflects how advertising as a commercial method helps establishes a stereoscape. Right Top: Another example of a mixture of advertising as a playable object. Right Bottom: The key cutting centre mixed with a historic building. Source: (Naughty Dog, 2011).

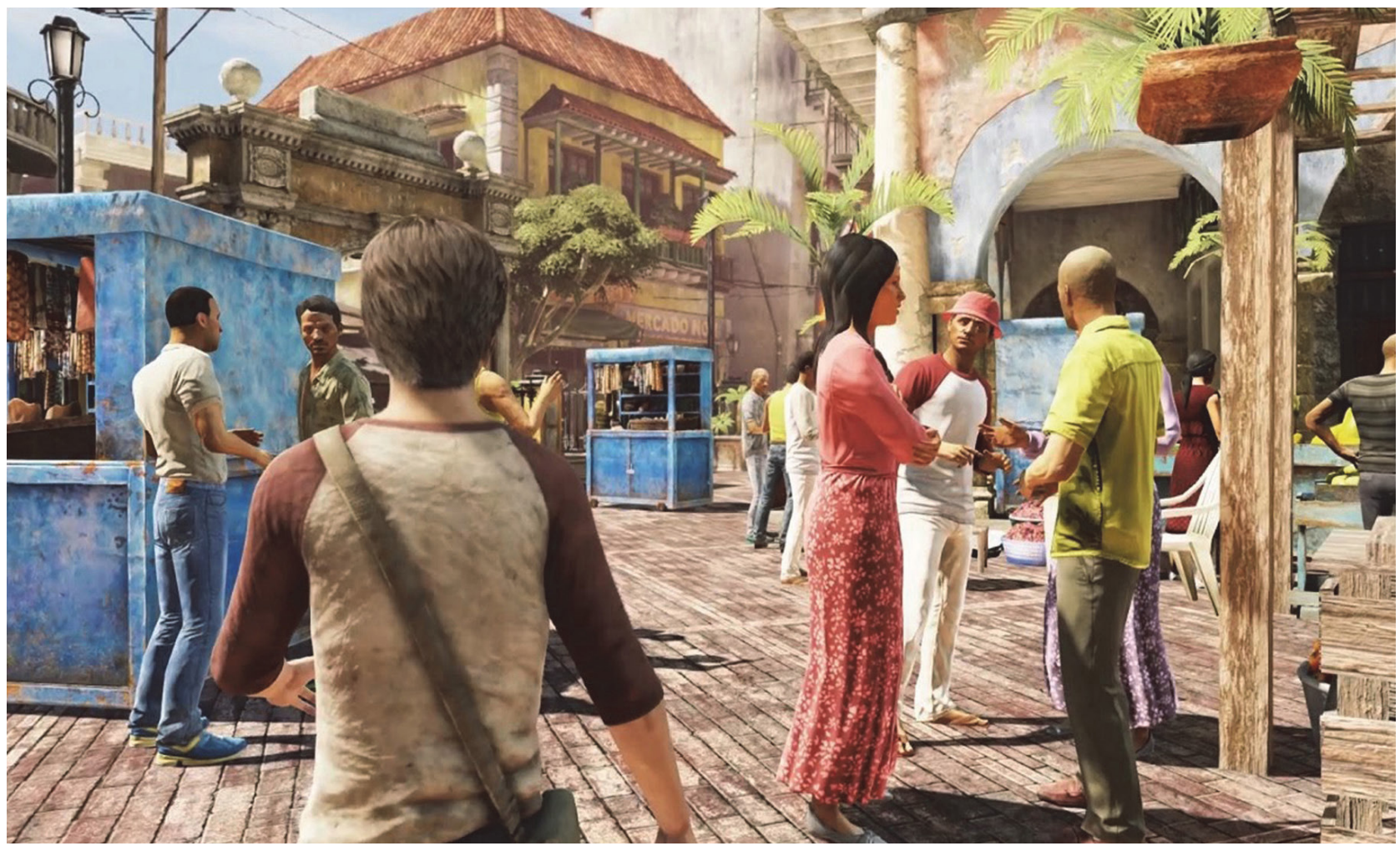

Figure 10. Screenshot of interaction in Plaza de la Habana (Aduana) in Uncharted 3: Drake's Deception. Source: (Naughty Dog, 2011).

the modification of the room in the 20th century, to serve as a shelter for the first infantry battalion of the Colombian Navy.

Another architectural or urban element represented in the game is part of the 47 half-point arches that protect the 24 vaults built at the end of the 17 th century named the "Bulwark of Santa Catalina". It was a deposit of gunpowder, provisions, and accoutrements. It had military use during the colony and in the independence served as a prison. After its restoration, handicrafts and antique shops, bars and galleries began to operate there. In U3:DD, the Bulwark of Santa Catalina is a akin to the Los Dulces Arcade, a well-known commercial historical arcade, shown with a dirty abandoned spatiality dedicated to the selling of meat, distanced from the real atmosphere of the neighbourhood as it is reality. As a background of the scenario, it is possible to see the Cathedral of Santa Catalina de Alejandria, which is adorned with security bars that give a prison look to this historical monument. (See Figs. 11 and 12) 

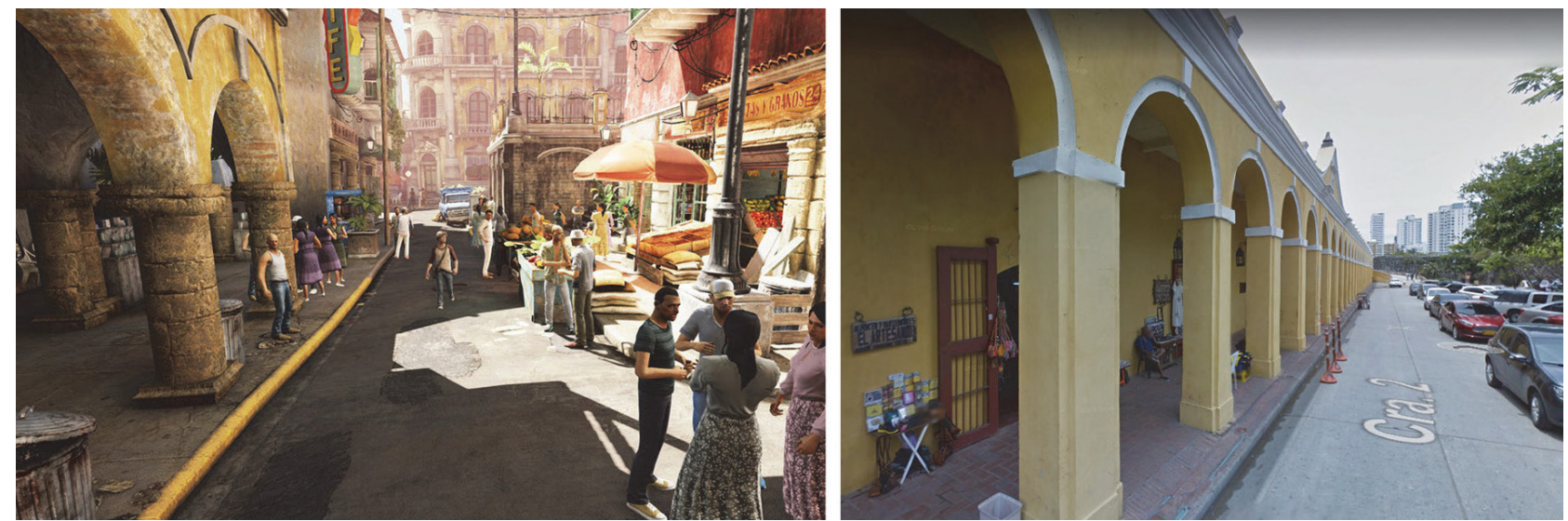

FiguRE 11. Comparative exercise of the representation in the videogame Uncharted 3: Drake's Deception. In the left, a screenshot in the walkthrough from the semi-open map of Cartagena; on the right, a virtual screenshot from Google street view (accessed Jul/2018), in the Bulwark of Santa Catalina.
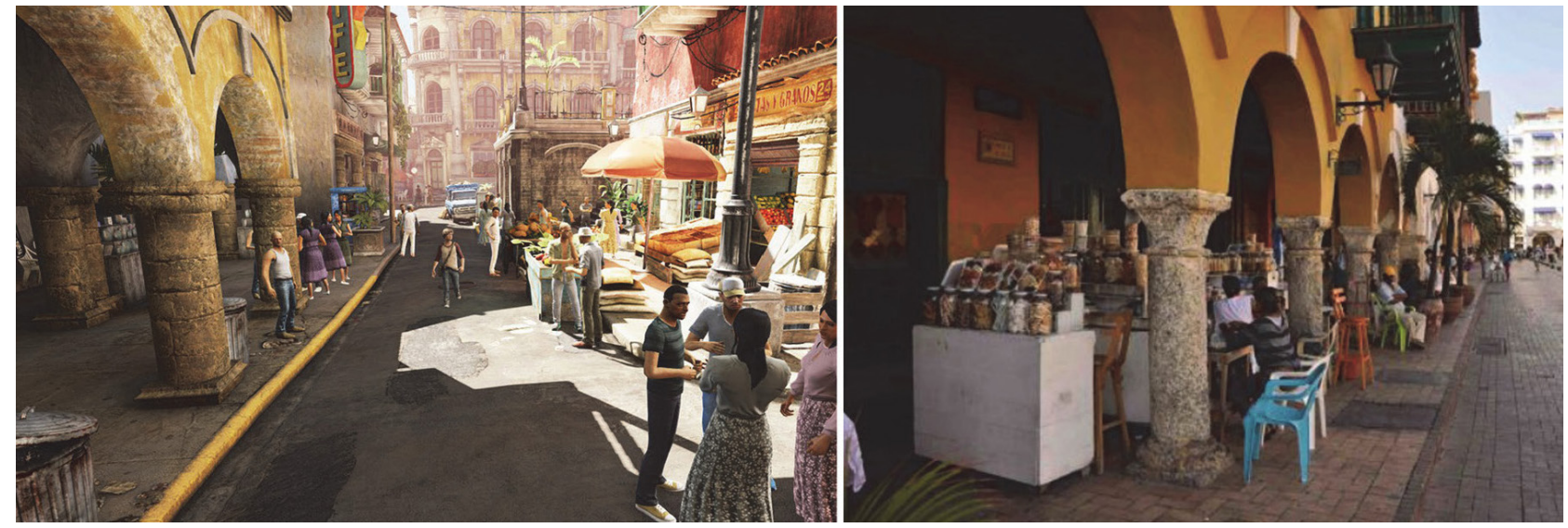

FIGURE 12. Comparative exercise of the representation in the videogame Uncharted 3: Drake's Deception. In the left, a screenshot in the walkthrough from the semi-open map of Cartagena; on the right, a virtual screenshot from Google street view (accessed Jul/2018), in the Portal de Los Dulces. Sources: (A): (Naughty Dog, 2011), Google Street View (Jul/2018). (B) (Naughty Dog, 2011), Google Street View (Jul/2018).

\section{BRIEF OF ANOTHER REALITY WITH (DI) SIMILAR CHARACTERISTICS: UNCHARTED 4: A THIEF'S END}

Uncharted 4: A Thief's End [U4:TE] was the penultimate instalment of the Uncharted saga and was released in 2016. The story follows the adventure of Drake and his brother Sam, who have to find the legendary treasure of pirate Henry Avery, hidden in north Madagascar. The game contains other scenarios set around the world: Panama, London, United States, Scotland and finally in Mexico. The scenarios that take place in Latin America are Chapter 2 and Chapter 5, and occur within a jail in Panama City, so do not develop commercial scenarios, but even in these chapters you can see stereotypical aesthetics when representing spatialities as in Latin American materialities. (See Fig. 13).

The final chapter or epilogue takes place on a Mexican beach in Yucatan, inside the house of Drake his wife and his daughter, so there is no concern to represent commercial scenarios. However, within the chapters that occur in Madagascar, there is one that is relevant for the reflections of this chapter. Chapter 11: Hidden to the Naked Eye includes the passage of Drake through commercial spaces in a city of Madagascar where we can observe some of the categories that have been mentioned in the text. The screen captures allowed to see the representation of Latin American spatial arrangement worn, disordered, objects fill the space, items such as beers, barrels and shopping baskets. These elements make up an abandoned post on the outskirts of a lot that is close to a Panamanian prison. However, these objects also appear in the office of the director of the prison, which has a narrative function and a social class different from what could be assumed from the outskirts of the prison. There are some types of objects that are used to build Latin American scenarios in general. 


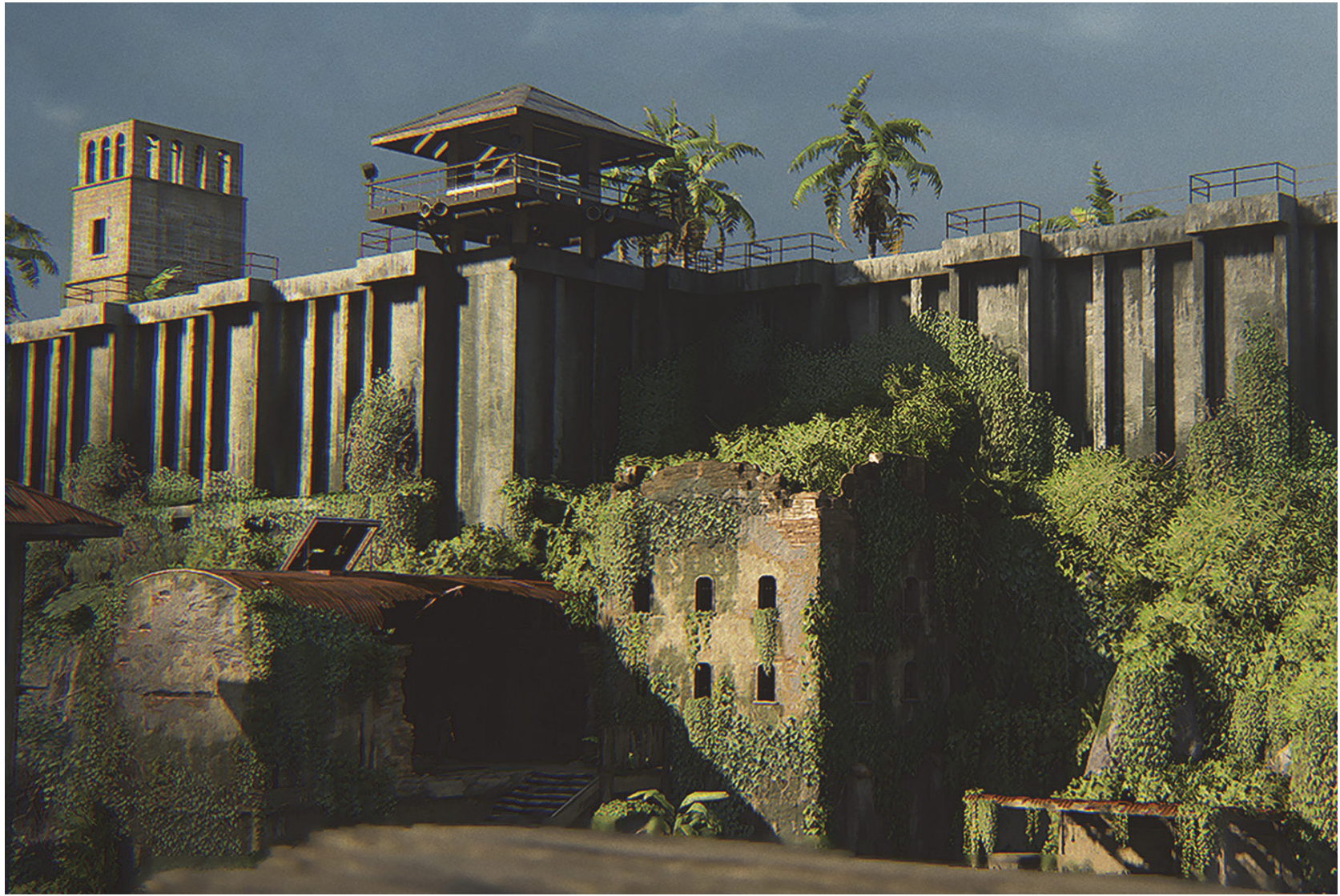

FIgURE 13. Panamá Prison. In this case, the building is in the paradisiac natural place, no urban scenarios and the materiality is conceived as a military Latin American massive and decadent facility. Videogame: Uncharted 4: A Thief's End. Source: (Naughty Dog, 2016).

In the Madagascar scenes, like those in Latin America, depictions of formal and informal businesses can be observed. At the beginning of Chapter 11, Drake traverses a space that is a Madagascan or informal market plaza. It is full of small stands carried by "natives" and covered each with a parasol. In the shops, fruits and meats are sold. Eventually, the player's path is blocked by saleswomen who approach him and persuade him to buy an apple. Drake wonders how prolific and artisanal the apple crops in Madagascar are, in such a way that street vendors have them as their primary commodity. Informal markets are in a physical state of decay. The health conditions represented are not standard; there are puddles of dirty water next to shops that sell food. The local's tents follow a uniform pattern: either a parasol covers them, or they are made up of wood and brass walls that do not vary much between them, suggesting that they are thought through 'type' objects that can be used to represent any trade of the place. However, formal trades in Madagascar are also described in this chapter. The dock is presented where large amounts of imports arrive or large quantities of exports depart. It is necessary to think that if the city is not Antananarivo, how coherent these dimensions are with the real maritime trade of Madagascar. (See Fig. 14)
There is also a motel where protagonists stay. The motel is a formal trade, in a state of deterioration much smaller than the food stalls that were seen before and that also presents an advertisement of itself in its facade. The interiors of the motel are also seen in the game, and although they are in a state of disrepair, it is less so than the informal trading plaza.

In this scenario, Nathan and his brother Sam drinks a beer. Beer has a brand that can be read: Bibilava Mena, which has a snake logo. This is a smart narrative decision as the word Bibilava refers to the snake Thamnosophis lateralis, ${ }^{11}$ an endemic species of Madagascar.

To account for how informal and formal establishments are articulated and represented in Madagascar serves as a point of comparison between what was found in Latin America. Parallels between poverty and urban commercial environments between Africa and America have been previously suggested by several scholars. ${ }^{12}$

\section{FINAL NOTES: COLISSIONS}

The stereotypes developed in the representation of the Latin American city are a distant construction of transferred cultural values. At the beginning of this work, the research concentrated on the architectural and urban form 

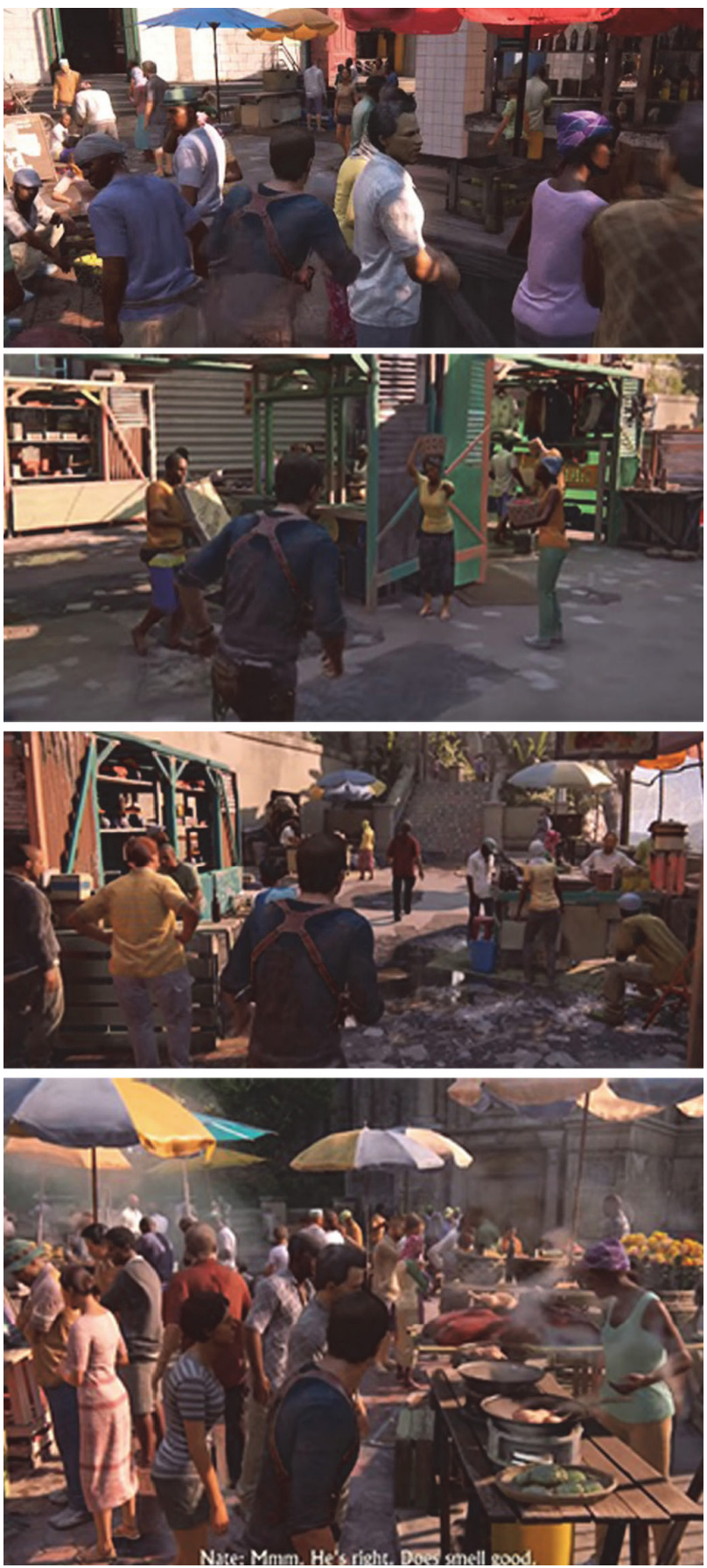

FIGURE 14. Collection of images (screenshot) in the Madagascar market interactions in the videogame: Uncharted 4: A Thief's End. Source: (Naughty Dog, 2016).

that is built in these scenarios. However, the discussion and debate between different members of the group deepened to have a transdisciplinary discussion, engaging other readings always in the confrontation and use of the videogame as a ludic and learning tool.

The word that encapsulates these findings is collision. The scenarios stereotyped from the cultural and social point of view, particularly those that come from commercial activity or an act of consumption (after all the video game is itself an element of mass consumption). These features are shown as contradictory collisions and synthesize a burden homogeneous from different origins. A city in the Caribbean, regardless of its historical background and all the layers that structure its society, are amalgamated as a single language full of similar characteristics. Havana, Cartagena or Rio de Janeiro, are the "same city" that constitute a broadly defined stereoscape.

Some characterizations have been mentioned throughout this article about other examples that can promote the use of the videogame as a potent tool in the teaching of the history and theory of architecture and the city. However, cases should be presented with due translations to allow the accurate and in-depth reading of these represented contexts. The findings in terms of form, space or even buildings in which the Latin American cities are portrayed, are dissimilar.

Video games as mass entertainment products represent a direct impact on these characterizations of our contexts. Old preconceptions remain latent and are highly visible in the homogenization of visual and social treatments. Undoubtedly, the repositioning of the wealth of the Global South countries represents an opportunity in the way we are perceived. Few games have tried to exemplify this complexity of the region in a critical scenario, sophisticated but at the same time suggestive.

The stereotypes conceived as processes of homogenization collide with the vast cultural heterogeneity of the society. In a global world, as Arjun Appadurai (1990) proposes, to transfer processes, identities or even images are increasingly common. Which is why we can speak about an "Americanization" of the economy in some contexts, or for the purposes of this article, the construction of digital landscapes that refers to a global imaginary lacking in local specificity. The "Havanization" of Cartagena de Indias, proposed by the conceptual artists of the game, demonstrates that global transfers as thematic packages, can be perfectly placed at the service of the experience of a videogame and its narrative. Our landscape is constructed, using the terms of O'Gorman (1972) as an invention of a digital Latin American to be consumed in a massive way.

However, the cases of Latin American cities are not studied for a mere reactive interest to the Eurocentric or American position. The cities of the global periphery, Latin American or from other regions of the Global South, receive the same treatment in the representation.

The context is always characterized by poverty, informality, and violence, colliding with a natural landscape that opens the discussion on political, economic or even social aspects, which may result in a debate outside the academic space. As a final example of this collisions, cities such as Caracas, capital of the Republic of Venezuela, used as part of the game Call of Duty: Ghost (Infinity Ward - Activision, 2013), can enhance the arguments presented about stereoscapes, when are exaggerated in favor of the game- 
play or the attractive profitability of the scenario into a poor, decayed modern city with a giant water dam in the middle of the Avila's mountains (referred to the Guri Dam in a different far part of the country). The visual and narrative collisions between the natural exuberant elements and a violent dictatorial government portrayed in the game, its again surrounded by poor favelas (See Fig. 15).

Nevertheless, it is essential to mention that this critical position on the stereotypes mainly analysed across the commercial landscapes is no necessary negative. When the digital atmosphere portrayed in the game was analyzed, particularly in spaces like the Aduana Square, it is possible to realize that this scenario is very close to what happens in that specific space in real life. The complexity of a video game in the construction of its digital environments synthetize an efficient use of spaces, images, sounds, and objects that in some cases represent a very assertive characterization of a place. It is possible to turn this opportunity into a positive tool of denunciation and to make our problems visible specially for non-academic communities. A visual common ground and explicit language that could be turned into a pedagogical and effective way communication.

The fact that Latin America is presented as a territory full of considerable shortcomings also reverses the possibility of making us visible in our opportunities. It is not a secret that the natural wealth of the region is part of the heritage, but many times and in particular, the ordinary citizen isn't aware of it.

Also, because Latin-American cities are complex societies, where mix uses, programs and functions, are increasingly present in every building or corner. The constant state of the emergency, the lack of resources and the political problems finds a creative resilient reaction to adapt and survive. U3: DD shows these mixed environments as a characterization that works for the game, but that could also become a potential in the face of decision making in our discipline. Mixed-use buildings, mixed heritage and contemporary programs, among others, are a repertoire of options for the city making.

This applies to Cartagena or Madagascar, or any other city that is portrayed in the videogames of this category and that belong to the peripheral region. The video game is a valuable balancing tool in recognition of our own characteristics (positive or negative). Moreover, a critical area in these research findings, and that undoubtedly was evident during the work developed in the research, are the social and gender stereotypes. These has been extensively worked from the social sciences, but it is essential to mix these categories of analysis with the next steps of this work.

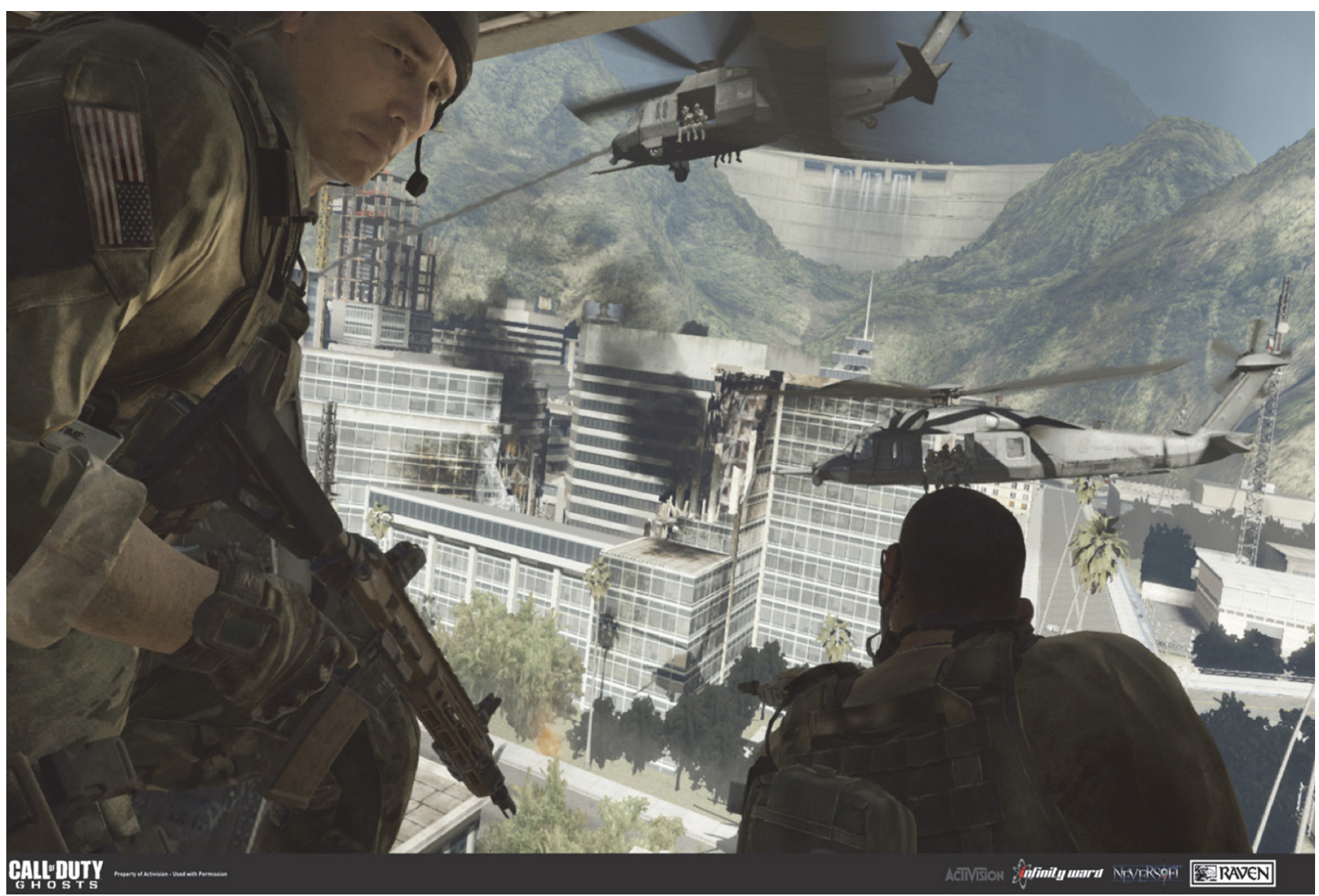

FIGURE 15. Screenshot of the Caracas military mission action. At the bottom is visible the collision between the Avila mountain system characterization and the big water dam from Guri (in Bolivar Department, Venezuela) in Call of Duty: Ghost. Source: (Infinity Ward - Activision, 2013). 
Taking these considerations into account, the conclusions or final notes, are presented not as closed paths in research or complete works. On the contrary, it is necessary to broaden the debate into two lines of work: one focused on the characterizations of stereotypes and another on the vast range of games whose total narrative thread is woven by historical resources (foundations, growths, expansions, invasions, among others) clearly differentiating the typology of video games, always focusing the effort into understanding the complexity of the Latin American city.

In this line of work and as an example of this continuity in the research about the Latin American cities in an early stage, is the case of Shadow of the Tomb Raider (Square Enix \& Eidos Montreal, 2018) specifically in the scenarios of Kuwaq Yaku and the Hidden City of Paititi. In these two cities the collision between the natural and cultural landscape is again represented, but in this case with new layers added in the narrative treatment. These fictional cities are the middle of the Peruvian Amazon and represent two sides of the Latin American characterization. In Kuwaq Yaku, an old town of fisherman that was almost destroyed by an oil company named Porvenir (which means Progress) transforming it into a place of criminal gangs and extreme poverty. Then Hidden City sheltered in the middle of the forest, allows the player to understand in detail from the old fishing and mining practices (salt), and to interact with the characters in Quetchua language and customs. This line of work proposes a growing path in the representations but also in a large and rich interdisciplinary debate.

Finally, the other line of work should address the use of videogame and all the software and hardware available for immersion, interactions, mapping and analysis. This approach needs to be reinforced into the schools of architecture as didactic, strategic and meaningful learning tools that help find new ways to refocus our disciplinary discourses and bring into question the past, present and future of Latin-American societies. Moreover, because the access to this technology can enhance the methodology described in this article. This disciplinary reposition proposed by Edgar Morin (1984) must be cantered in the revision of the complex reality and the multidisciplinary approach of our history but also by the uncertainty of the future from our field of knowledge.

\section{ACKNOWLEDGMENTS}

This paper is based on the activities of the research seedbed DigitalScapes funded by Universidad de Los Andes, Department of Architecture, Faculty of Architecture and Design, Colombia; coordinated by professors Claudio J. Rossi (Venezuela) and Manuel Sánchez García (Spain). But also, as a part of the research and library work thanks to Department of Architecture and Design at the Politecnico di Torino, Italy, in my position as Visiting Professor (2018-2019). The following graduate and undergraduate students participated in the analysis and data recollection activities whose results are shown in this paper:
Álvaro Gómez - Former Graduate Research Assistant, Master of Architecture, Architecture Department, Faculty of Architecture and Design, Universidad de Los Andes. Mail: aa.gomezo@uniandes.edu.co

Santiago Ojeda - Graduate student, Master in Digital Humanities, Social Sciences Faculty, Universidad de Los Andes. Mail: s.ojeda37@uniandes.edu.co

Susana Hernández - Undergraduate research assistant, Design Department, Faculty of Architecture and Design, Universidad de Los Andes. Mail: s.hernandezt@ uniandes.edu.co

Manuel Alejandro Hernández - Undergraduate research assistant, Architecture Department, Faculty of Architecture and Design, Universidad de Los Andes. Mail: ma.hernandez2@uniandes.edu.co

Alejandra Rivera - Undergraduate research assistant, Architecture Department, Faculty of Architecture and Design, Universidad de Los Andes. Mail: a.riveram@uniandes.edu.co

\section{NOTES}

1 Frederick Law Olmstead wrote this in his letter of resignation to the Board of Commissioners of Central Park, Jan/22/1861; Cit. in: Olmstead, Frederick Law Jr.; Kimball, Theodora. "Frederick Law Olmstead, Landscape Architect 1822 - 1903". Benjamin Blom Publishers, New York, 1970; P. 310.

2 Scholars have provided many names to explain the digitally build FIGURE 15. Screenshot of the Caracas military mission action. At the bottom is visible the collision between the Avila mountain system characterization and the big water dam from Guri (in Bolivar Department, Venezuela) in Call of Duty: Ghost. Source: (Infinity Ward - Activision, 2013). environments. Papadopoulos et. al. use Gamespace, not only to talk about the form of elements or components of this scenarios but also to make and approach to implicit laws that enhance the narrative and the immersive experience: gravity, temperature, among others; elements that actually does not exist but are materialized in the digital world. Therefore, definitions like digital cities, digital landscapes, digitalscapes or digital environments can be summarized into the idea of scenario (see footnote 4), landscapes or environments for the purpose of this article.

3 This term has been widely used in reference to the methodologies of analysis of the city from the perception point of view and was adopted by the book of the same name by Kevin Lynch (1998). The author establishes a series of categories that, from the exploration and interaction with the inhabitants of a city, allows the construction of an approximation of the imaginary of that environment. In doing so, Lynch promotes a new way of approaching the city from the knowledge of those who inhabit it.

4 The idea of scenarios is important in the spatial understanding of a videogame because it promotes the definition of a player (spectator) and a place where interactions with the viewer are developed (stage).

5 According to Activision: "Call of Duty: Black Ops sold 5.6 million copies in 24 hours, making it the biggest entertainment launch ever"- Cit. in. Wired Magazine (https://www.wired. com/2010/11/black-ops-sales/) accessed: 22/August/2018

6 This is a categorization used informally by the video game industry and players. It refers to the video games carried out by the big developers that usually takes long periods of development and involves large budgets.

7 The game has some of the missions in Panamá and México, but there is a large interactive part in Madagascar - África.

8 Walled city founded in 1533, capital of the Department of Bolívar in Colombia and named UNESCO World Heritage Site in 1984. 
9 These visual memoirs are extensive and prolific documents, built from meetings and gameplay screenshots that were organized in a continuous form and then classified regarding the different finds. This article tries to mention most of these findings and its documentary base rest as the archive of the following stages of the seedbed. In the final notes, it is mentioned that this is a work process that is growing every day, adding up more undergrad and postgrad students from different disciplines interested in this methodology and thematic.

10 International Labour Organization, ILO (OIT). (2018). "Mujeres y Hombres en la Economía Informal: Un Panorama Estadistico". Third Edition. Ginebra.

11 Encyclopedia of Life. "Lateral Water Snake-Bibilava Lateralis-Overview”. Encyclopedia of Life, accessed April 20, 2018, http://eol.org/pages/791667/overview.

12 Satterthwaite, David. (2003). "The Links between Poverty and the Environment in Urban Areas of Africa, Asia, and Latin America" The ANNALS of the American Academy of Political and Social Science 590, no. 1 (November 1, 2003): 73-92.

\section{REFERENCES}

Appadurai, Arjun. (1990) "Disjuncture and Difference in the Global Cultural Economy". Theory, Culture \& Society, 7(2-3) pp. 295-310.

Bargh, John A.; Chen, Mark and Burrows, Lara. (1996) "Automaticity of Social Behavior: Direct Effects of Trait Construct and Stereotype Activation on Action". Journal of Personality and Social Psychology 1996, Vol. 71, No. 2 pp. 230-244.

Batty, Michael (1990) "Invisible Cities". Environment and Planning B: Planning and Design, 17 pp. 127-130.

Bauman, Zygmunt (2013) Liquid Modernity. New Jersey: Wiley.

Braudel, Fernand (1978) Histoire Et Sciences Sociales. Pour Une Économie Historique Les Responsabilités De l'Histoire Histoire Et Sociologie L'apport De l'Histoire Des Civilisations Unité Et Diversité Des Sciences De L’homme. Madrid: Alianza Editorial.

Castells, Manuel (1992) The Informational City: Economic Restructuring and Urban Development. New Jersey: Wiley.

Chandra, Priyank (2017) "Informality and Invisibility: Traditional Technologies as Tools for Collaboration in an Informal Market". CHI '17: Proceedings of the 2017 CHI Conference on Human Factors in Computing Systems, Denver, pp. 4765-4775.

Chávez, Daniel (2010) "El Coronel No Tiene Con Quien Jugar: Representaciones Latinoamericanas En La Literatura Y El Videojuego". Arizona Journal of Hispanic Cultural Studies 14 pp. 159-76.

Cullen, Gordon (1995) The Concise Townscape. London: Architectural Press.

Di Felice, Massimo (2012). Paisajes Posurbanos. El Fin De La Experiencia Urbana Y Las Formas Comunicativas Del Habitar. Córdoba: Editorial Universidad Nacional de Córdoba - Ediciones el Copista.

Dorado, Mariano (2018) Movimiento y jugabilidad. Articulación espacial en videojuegos 2D. Proyecto Fin de Carrera / Trabajo Fin de Grado, E.T.S. Arquitectura (UPM).

Frederick Law Jr. and Kimball, Theodora (1970) Frederick Law Olmstead, Landscape Architect 1822 - 1903. New York: Benjamin Blom Publishers.

Graham, Steven; Simon, Marvin (2002) Telecommunications and The City: Electronic Spaces, Urban Places. Abligdon: Routledge.

International Labour Organization, ILO (OIT) (2018) Mujeres y Hombres en la Economía Informal: Un Panorama Estadístico. Geneva: Third Edition.

Kassin, Saul; Fein, Steven and Markus, Hazel Rose (2010) Social Psychology. Boston: Cengage Learning.

Lévy, Pierre (1998). Becoming Virtual: Reality in the Digital Age. New York: Plenum Trade.

Lynch, Kevin (1998) La Imagen De La Ciudad. Barcelona: Gustavo Gili.
Morin, Edgar (1984) Ciencia con Conciencia. Barcelona: Anthropos,

Morin, Edgar (1999) La Cabeza Bien Puesta: Repensar la Reforma. Reformar el Pensamiento. Buenos Aires: Ediciones Nueva Visión.

Negroponte, Nicholas (1995) Being Digital. New York: Vintage Books.

Nelson, Michelle R. (2002) "Recall of Brand Placements in Computer/Video Games". Journal of Advertising Research 42 (2): pp. 80-92.

O'Gorman, Edmundo (1961) “The Invention of America an Inquiry into the Historical Nature of the New World and the Meaning of its History". Westport: Greenwood Press.

Papadopoulos, Spiros and Malakasioti, Angeliki (2012) "Arcade Games as a Qualitative". The sixth edition of the European Symposium on Research in Architecture and Urban Design. Oporto: Faculdade de Arquitectura da Universidade do Porto.

Penix-Tadsen, Phillip (2013) "Why We Should Take Video Games Seriously (and When We Shouldn't)". Latin American Research Review 48 (1) pp. 174-190.

Penix-Tadsen, Phillip (2016) Cultural Code: Video Games and Latin America. Cambridge: MIT Press.

Pérez Indaverea, Ma. Aránzazu (2012) "Espacios Urbanos En El Videojuego: París Como Escenario De Tensión”. Ángulo Recto. Revista de estudios sobre la ciudad como espacio plural 4 (1) pp. 31-48.

Polano, Sergio (2016) "Gli Ultimi Nidi Delle Aeronvi”, Revista Casabella 867 (n.11 / 2016) pp. 3-13.

Roman, Ediberto (2000) "Who Exactly Is Living La Vida Loca: The Legal and Political Consequences of Latino-Latina Ethnic and Racial Stereotypes in Film and Other Media". Journal of Gender, Race and Justice. pp. 4: 37.

Satterthwaite, David (2003) "The Links between Poverty and the Environment in Urban Areas of Africa, Asia, and Latin America". The ANNALS of the American Academy of Political and Social Science 590, no. 1 (November 1, 2003) pp. 73-92.

Sennett, Richard (1990) The Conscience of the Eye. New York: Knopf.

Souza e Silva, Adriana de and Sutko, Daniel M. (2008) "Playing Life and Living Play: How Hybrid Reality Games Reframe Space, Play, and the Ordinary". Critical Studies in Media Communication, 25:5 pp. 447-465.

Tsukamoto, Saori and Fiske, Susan (2017) "Perceived threat to national values in evaluating stereotyped immigrants". Journal of Social Psychology, 2018;158(2) pp. 157-172.

The National Archives (2015), AIR 11/237 (retrieved from: https:// history.blog.gov.uk/2015/01/19/air-raid-casualties-in-the-firstworld-war/ (Accessed: Aug/2018).

Unali, Maurizio (2014) Atlante Dell'Abitare Virtuale. Il Disegno della Città Virtuale, fra Riserca e Didattica. Pescara: Università di D'Annunzio University of Chieti-Pescara.

Venturi, Robert; Scott-Brown, Denise abd Izenour, Steven (1972) Learning From Las Vegas. Cambridge: MIT Press.

Virilio, Paul (1995) The Art of the Motor. Minnesota: University of Minnesota Press.

\section{Videogames mentioned:}

Call of Duty: Black Ops (Treyarch - Activision, 2010)

Call of Duty: Ghost (Infinity Ward - Activision, 2013)

Max Payne 3 (Rockstar Games, 2012)

Papo y Yo (Minority Media Inc, 2012)

Pitfall! (David Crane -Activision, 1982)

Shadow of the Tomb Raider (Square Enix \& Eidos Montreal, 2018)

The Order 1886 (Ready at Dawn - SCE Santa Monica Studio, 2015)

Tropic (Gathering of Developers, 2001)

Uncharted: Drake's Fortune (Naughty Dog, 2007)

Uncharted 3: Drake's Deception (Naughty Dog, 2011)

Uncharted 4: A Thief's End (Naughty Dog, 2016) 